\title{
Influenza epidemiology and influenza vaccine effectiveness during the 2015-2016 season: results from the Global Influenza Hospital Surveillance Network
}

Joan Puig-Barberà ${ }^{*}$ (D), Ainara Mira-Iglesias ${ }^{1}$, Elena Burtseva ${ }^{2}$, Benjamin J. Cowling ${ }^{3}$, Unal Serhat ${ }^{4}$, Guillermo Miguel Ruiz-Palacios ${ }^{5}$, Odile Launay ${ }^{6}$, Jan Kyncl${ }^{7}$, Parvaiz Koul ${ }^{8}$, Marilda M. Siqueira ${ }^{9}$, Anna Sominina ${ }^{10}$ and on behalf of the Global Influenza Hospital Surveillance Network

\begin{abstract}
Background: The Global Influenza Hospital Surveillance Network is an international platform whose primary objective is to study severe cases of influenza requiring hospitalization.

Methods: During the 2015-2016 influenza season, 11 sites in the Global Influenza Hospital Surveillance Network in nine countries (Russian Federation, Czech Republic, Turkey, France, China, Spain, Mexico, India, and Brazil) participated in a prospective, active-surveillance, hospital-based epidemiological study. Influenza infection was confirmed by reverse transcription-polymerase chain reaction. Influenza vaccine effectiveness (IVE) against laboratory-confirmed influenza was estimated using a test-negative approach.
\end{abstract}

Results: 9882 patients with laboratory results were included of which 2415 (24.4\%) were positive for influenza, including 1415 (14.3\%) for A(H1N1)pdm09, 235 (2.4\%) for A(H3N2), 180 (1.8\%) for A not subtyped, 45 (0.5\%) for B/Yamagata-lineage, 532 (5.4\%) for BNictoria-lineage, and 33 (0.3\%) for B not subtyped. Of included admissions, 39\% were < 5 years of age and $67 \%$ had no underlying conditions. The odds of being admitted with influenza were higher among pregnant than nonpregnant women (odds ratio, 2.82 [95\% confidence interval (CI), 1.90 to 4.19]). Adjusted IVE against influenza-related hospitalization was $16.3 \%$ (95\% Cl, 0.4 to 29.7). Among patients targeted for influenza vaccination, adjusted IVE against hospital admission with influenza was $16.2 \%$ ( $(95 \% \mathrm{Cl}$, -3.6 to 32.2$)$ overall, $23.0 \%(95 \% \mathrm{Cl},-3.3$ to 42.6$)$ against $\mathrm{A}(\mathrm{H} 1 \mathrm{~N} 1)$ pdm09, and $-25.6 \%(95 \% \mathrm{Cl},-86.3$ to 15.4$)$ against BNictoria lineage.

Conclusions: The 2015-2016 influenza season was dominated by A(H1N1)pdm09 and B/Nictoria-lineage. Hospitalization with influenza often occurred in healthy and young individuals, and pregnant women were at increased risk of influenzarelated hospitalization. Influenza vaccines provided low to moderate protection against hospitalization with influenza and no protection against the predominant circulating B lineage, highlighting the need for more effective and broader influenza vaccines.

Keywords: Influenza, Virus, Surveillance, Vaccine, Hospitalization, Epidemiological study

\footnotetext{
*Correspondence: jpuigb55@gmail.com

${ }^{1}$ Fundación para el Fomento de la Investigación Sanitaria y Biomédica de la

Comunidad Valenciana, FISABIO, Valencia, Spain

Full list of author information is available at the end of the article
}

C The Author(s). 2019 Open Access This article is distributed under the terms of the Creative Commons Attribution 4.0 International License (http://creativecommons.org/licenses/by/4.0/), which permits unrestricted use, distribution, and reproduction in any medium, provided you give appropriate credit to the original author(s) and the source, provide a link to the Creative Commons license, and indicate if changes were made. The Creative Commons Public Domain Dedication waiver (http://creativecommons.org/publicdomain/zero/1.0/) applies to the data made available in this article, unless otherwise stated. 


\section{Background}

Influenza surveillance is essential for tracking and controlling influenza infections and for assessing influenza vaccine effectiveness (IVE). Since 2012, the Global Influenza Hospital Surveillance Network (GIHSN) has run an annual prospective, active-surveillance, hospital-based study to collect epidemiological and virological data on influenza [1]. The aim of the GIHSN is to improve understanding of influenza epidemiology to better inform public health policy decisions.

During the 2015-2016 influenza season, the GIHSN included 11 coordinating sites and 27 hospitals in nine countries (St. Petersburg and Moscow, Russian Federation; Prague, Czech Republic; Ankara, Turkey; Paris, France; Beijing, China; Valencia, Spain; Tlalpan, Mexico; Jammu and Kashmir, India; and Fortaleza and Curitiba, Brazil). All sites in the GIHSN share a common core protocol, follow standard operating procedures, use a shared questionnaire to collect patient information, and perform reverse transcription-polymerase chain reaction to confirm influenza infection [1]. Thus, the GIHSN can attain large sample sizes and relevant data on severe influenza and IVE among hospitalized individuals from geographically disperse regions. In addition, several limitations of other surveillance systems are avoided or adjusted for, such as non-systematic sampling and incomplete case ascertainment, as well as a lack of comparison groups, adjustment for confounders, and consensus about case definitions [2-4]. Results have been published for the GIHSN's first three seasons (2012-2013 [5, 6], 2013-2014 [7], and 2014-2015 [8]). Here, we present the influenza epidemiology and IVE results by age and influenza strain for the 2015-2016 influenza season.

\section{Methods}

\section{Study design}

The GIHSN was initiated by Sanofi Pasteur in 2011 to fill the gap in influenza epidemiology and public health knowledge. The GIHSN is a public-private partnership between Sanofi Pasteur and several institutions that are affiliated with national health authorities (including the WHO National Influenza Centers, national ministries of health, and China's Centers for Diseases Control and Prevention). Each of these institutions acts as a coordinating site and supervises a local network of hospitals. Not-for-profit institutions with proposals aligned with the GIHSN scope and study design are eligible to apply for grants from the Foundation for Influenza Epidemiology. Sanofi Pasteur participated in the design of the study but did not participate in the collection, management, or analysis of data.

The methodology for the GIHSN study has previously been described in detail $[1,5,6]$. Briefly, the study included patients who had been admitted to one of the participating hospitals for acute illness possibly related to influenza within the last $48 \mathrm{~h}$. The patients had to be residents in the predefined hospital's catchment area for at least 6 months, not institutionalized, and not discharged from a hospital within 30 days of the current admission. Onset of symptoms had to be within 7 days prior to admission. Acute illness in patients aged $\geq 5$ years had to meet the European Centre for Disease Prevention and Control clinical case definition of influenzalike illness (ILI) [9]; include one of the following general symptoms: fever or feverishness, malaise, myalgia or headache; and include one of the following respiratory complaints: shortness of breath, sore throat, or cough. Patients aged $<5$ years were recruited if they presented with any of the signs and symptoms described in Additional file 1: Table S1. Patient eligibility was assessed by research staff using admission rolls, clinical records, and information obtained from the patient after consent. Each site defined the sample collection period according to previous experience in local influenza epidemics (see Additional file 2: Table S2). For each patient, a common standardized questionnaire was completed by face-toface interview or by searching clinical records. Collected information included age, sex, number of chronic underlying conditions, previous admissions to hospital in the last 12 months, number of visits to a general practitioner in the last 3 months, smoking habits, socioeconomic class (according to occupation), days from onset of symptoms to swabbing, and epidemiological week at admission. The influenza vaccination status of each patient was also collected by face-to face interview, patient records, clinical records, or registries, including the name of the vaccine received and the date of vaccination. Two respiratory swabs were taken from each patient (nasal and nasopharyngeal swabs from patients < 14 years, pharyngeal and nasopharyngeal swabs from patients $\geq 14$ years) and combined to detect the presence of influenza A (H1N1pdm09 and H3N2 subtypes) and B (Yamagata and Victoria lineages) by real-time reverse-transcription polymerase chain reaction. All included patients, or their parents or legal guardians, provided written informed consent.

\section{Statistical analysis}

Statistical analyses were performed using Stata version 14.2 (College Station, TX, USA). Differences between categories were estimated by the Pearson Chi-square or Fisher exact test as appropriate. When comparing nested models, $P$-values for interactions were obtained by likelihood ratio test. $P$-values below 0.05 were considered statistically significant. Conditional plots were used to describe complex relationships between age, chronic conditions and influenza infection [10].

IVE was estimated using the test-negative approach as $(1$ - odds ratio $[\mathrm{OR}]) \times 100$, where the OR was calculated 
by mixed effects logistic regression comparing the vaccine coverage rates between influenza-positive and influenza-negative cases, after adjusting for potential confounders. Appropriate variables were included depending on the model. For the IVE model, age was divided into deciles and modelled using restricted cubic splines; sex was a categorical variable; social class was a categorical variable with four levels (qualified, skilled, low or unskilled, and unknown); number of comorbidities was a categorical variable with three levels (none, one, more than one); vaccination status had two levels (yes/no); time from onset to swab was a categorical variable with three levels ( 0 to 4,5 to 7,8 to 9 ); epidemiological week at admission was modelled using restricted cubic splines. The number of knots for age and epidemiological week was chosen using the Akaike information criterion [11]. IVE was not estimated for individual influenza vaccines. Heterogeneity between sites was controlled by including the site as a random effect in the models. All included patients were considered in the descriptive analysis, but records with missing values for outcome, exposure, or with potential confounders, and individuals with contraindications for vaccination or with previous influenza infections, were excluded from the IVE analysis. IVE values were considered heterogeneous if the $\mathrm{I}^{2}$ statistic was $>50 \%$.

\section{Results}

\section{Patients included in the epidemiological analysis and identified viruses}

A total of 18,360 eligible admissions were identified by the 11 coordinating sites during the 2015-2016 influenza season. Of these, 9882 admissions (53.8\%) met the inclusion criteria and were included in the study (Table 1). The main reasons for exclusion were the absence of ILI symptoms for subjects $\geq 5$ years of age $(n=3886$, $21.2 \%$ ) and recruitment during weeks without influenza circulation $(n=1524,8.3 \%)$. No cases at the Fortaleza site met the inclusion criteria.

Approximately $24 \%$ of the included patients were positive for influenza. The most common strain detected was $\mathrm{A}(\mathrm{H} 1 \mathrm{~N} 1) \mathrm{pdm} 09$ (58.6\% of influenza positives), followed by $\mathrm{B} /$ Victoria-lineage $(22.0 \%)$ and $\mathrm{A}(\mathrm{H} 3 \mathrm{~N} 2)$ (9.7\%). Approximately $9 \%$ of influenza-positive samples could not be subtyped.

\section{Description of the 2015-2016 influenza season across sites} Influenza infections were detected over 38 weeks, with the peak at week 4 of 2016 (Fig. 1). The earliest start of the influenza season was in Moscow (week 48 of 2015), where influenza-positive admissions occurred over a span of 27 weeks in two waves, the first due to $\mathrm{A}(\mathrm{H} 1 \mathrm{~N} 1)$ pdm09 and the second due to B/Victoria-lineage. The latest influenza-positive admission (week 33 of
2016) was in Curitiba, Brazil, although few cases of confirmed influenza were detected at that site.

The proportion of samples positive for influenza differed between sites from $2.7 \%$ in Curitiba to $46.9 \%$ in Mexico (Table $1 ; P<0.0001$ by test of homogeneity, equal odds). $\mathrm{A}(\mathrm{H} 1 \mathrm{~N} 1)$ pdm09 was the most frequently detected influenza virus in St. Petersburg $(71.2 \%$ of positives), Moscow (68.1\%), Czech Republic (54.8\%), Turkey $(47.6 \%)$, France $(56.8 \%)$, Valencia (51.4\%), Mexico (46.7\%), and Curitiba (81.3\%) (Table 1). B/Victoria-lineage was the second-most frequently detected influenza virus in Moscow (22.6\%), St. Petersburg (13.0\%), France (36.4\%), Valencia $(29.0 \%)$ and Curitiba (18.8\%) and was the most common influenza virus in Beijing (43.9\%). Influenza $\mathrm{A}(\mathrm{H} 3 \mathrm{~N} 2)$ was the predominant strain in India (48.6\%) (Fig. 1 and Table 1).

\section{Main characteristics of included patients}

Of the 9882 included admissions, $39.0 \%$ were $<5$ years of age, $38.0 \%$ were $5-64$ years of age, and $23.0 \%$ were $\geq 65$ years of age (Table 2). Just over half of the included patients were male $(n=5380 ; 54.4 \%)$ and more than half $(615 / 1051 ; 58.5 \%)$ of the admitted women $15-45$ years of age were pregnant ( $6.2 \%$ of all included patients).

Approximately one-third $(n=3276 ; 33.2 \%)$ of the admissions had chronic conditions, most of which were cardiovascular disease $(n=1888 ; 19.1 \%)$, chronic obstructive pulmonary disease $(n=1039 ; 10.5 \%)$, diabetes ( $n=840 ; 8.5 \%)$, renal impairment $(n=454 ; 4.6 \%)$, and asthma ( $n=424 ; 4.3 \%)$. Immunodeficiency, neuromuscular disease, active neoplasm, liver disease, and autoimmune disease accounted for $<4 \%$ of patients with chronic conditions.

Most patients $(n=7168 ; 72.5 \%)$ had not been hospitalized in the 12 months before the current admission. Half of the hospitalized adults ( $\geq 18$ years old) had never smoked $(n=2548 ; 50.1 \%), 27.6 \%(n=1404)$ were past smokers, and $22.4 \%(n=1138)$ were current smokers. According to World Health Organization criteria [12], $14.4 \%(n=1425)$ of patients were obese. Approximately $20 \%$ of older adults ( $\geq 65$ years of age) had a functional impairment status between moderate and total on the Barthel Index.

Swabs were obtained within 4 days after the onset of symptoms in $67.9 \%$ of patients $(n=6712)$. The seasonal influenza vaccine had been administered to $1525 \mathrm{pa}$ tients (15.4\%), most of whom $(96.9 \%)$ had been vaccinated at least 14 days before the onset of ILI symptoms.

\section{Characteristics of included patients across sites}

Proportions of younger patients were highest in Curitiba (median age $=1$ years) and St. Petersburg (median age $=$ 2 years) (Table 2). Children $<5$ years of age accounted for $72.1 \%$ of included admissions in Curitiba and $65.8 \%$ 


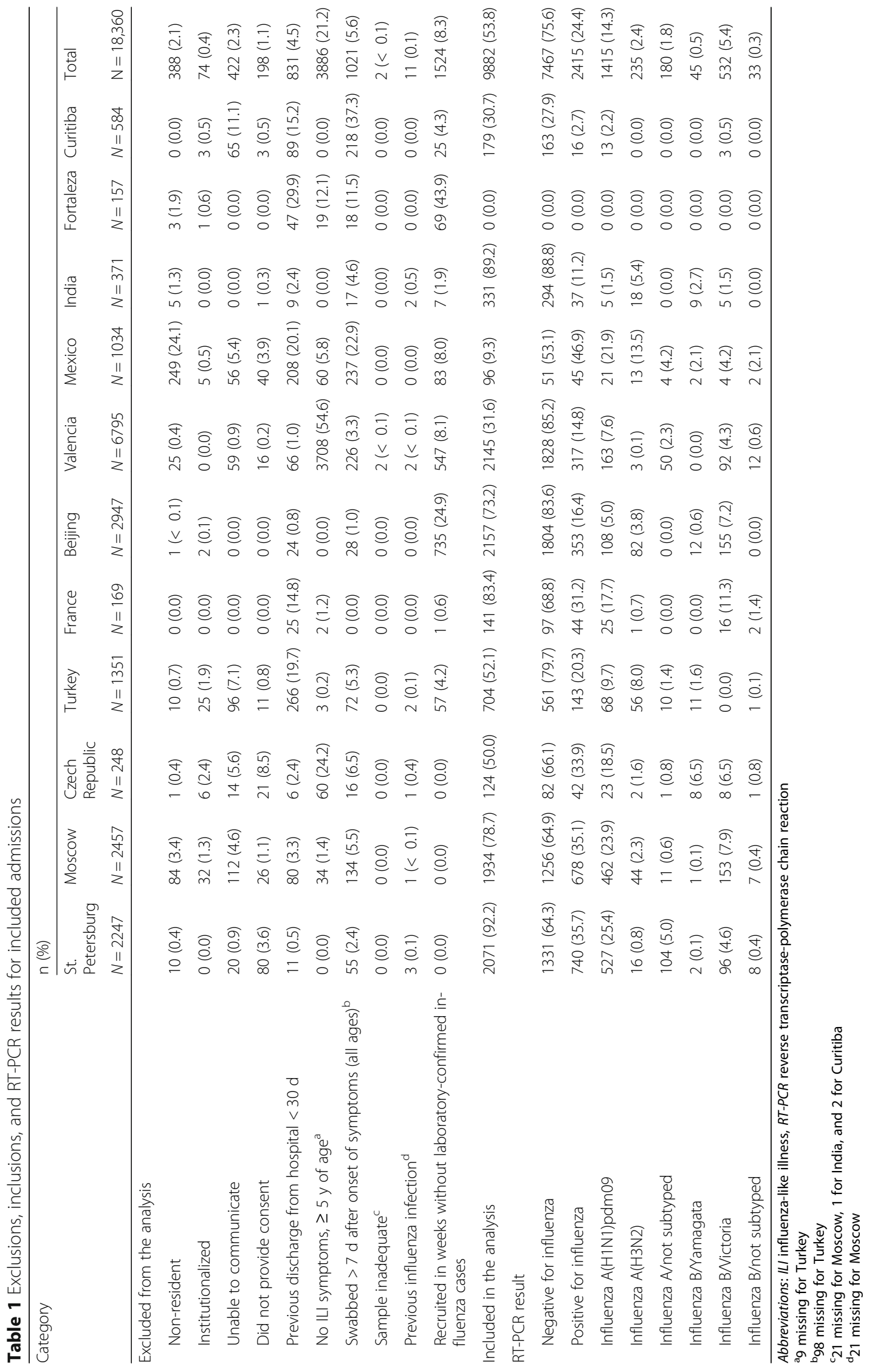




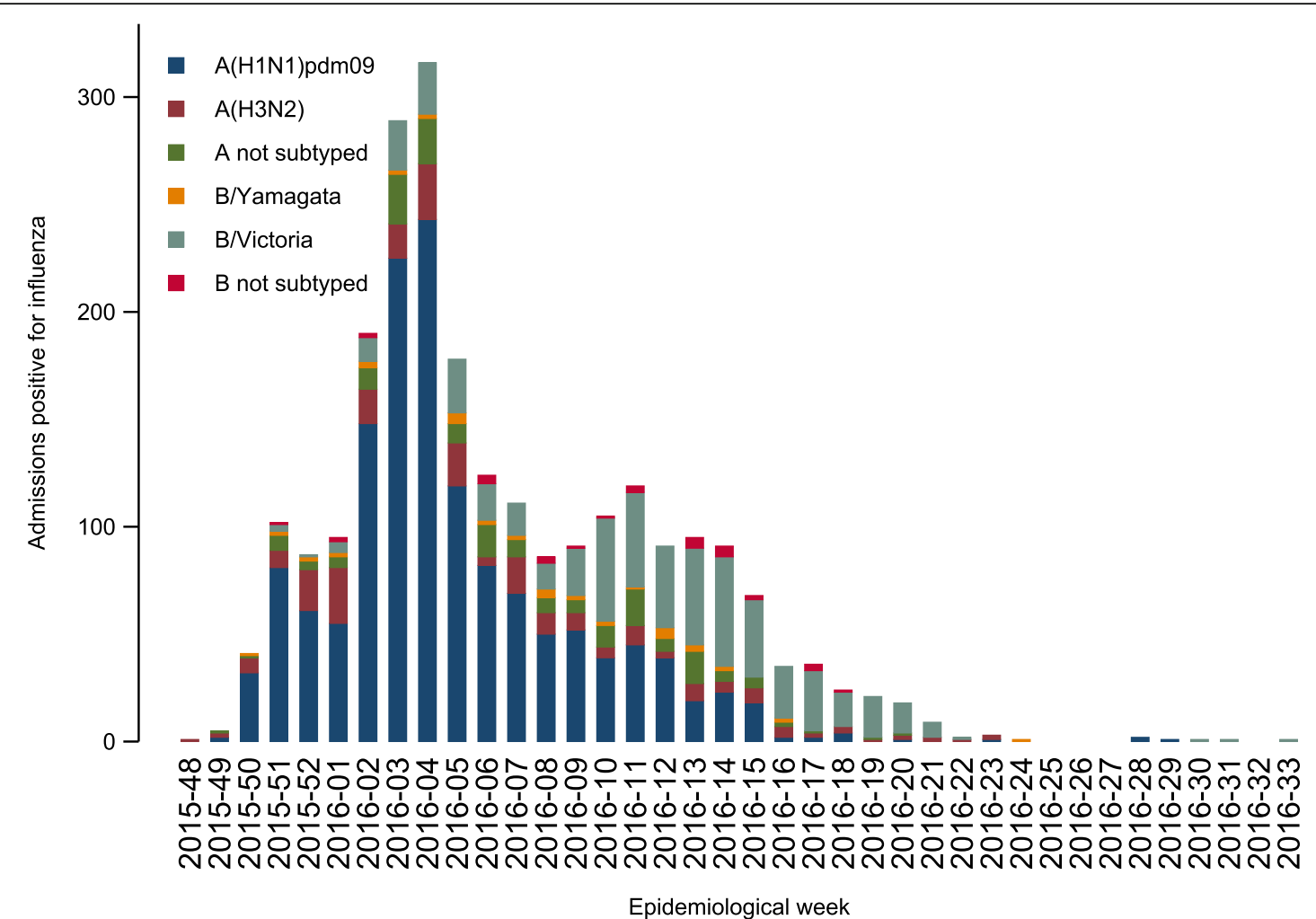

St. Petersburg

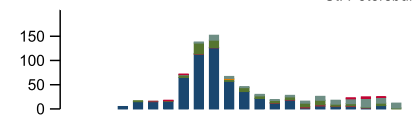
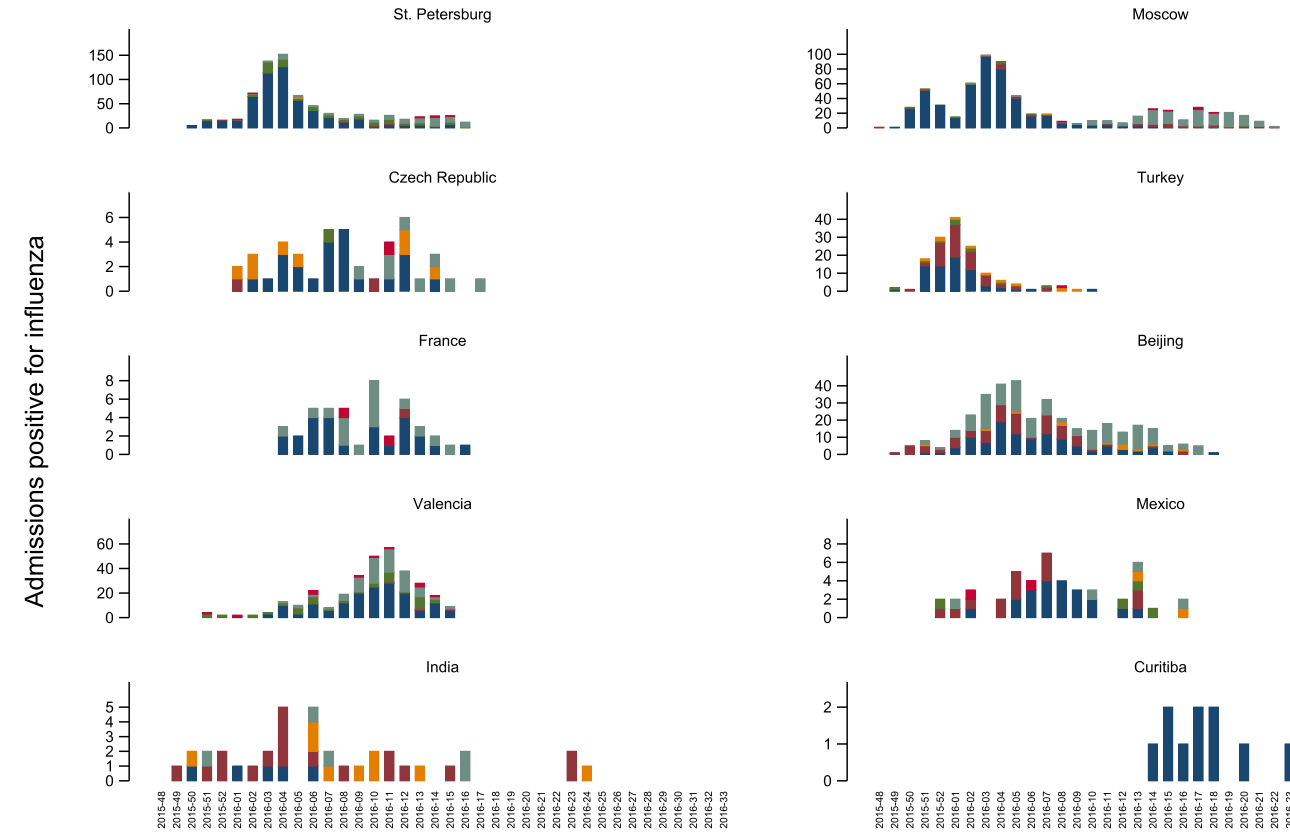

Epidemiological week

- $\mathrm{A}(\mathrm{H} 1 \mathrm{~N} 1) \mathrm{pdm09} \quad \mathrm{A}(\mathrm{H} 3 \mathrm{~N} 2) \quad$ A not subtyped

B/Yamagata

- B/Victoria

- B not subtyped

Fig. 1 Admissions with influenza by epidemiological week and virus type, subtype, or lineage overall and by site 


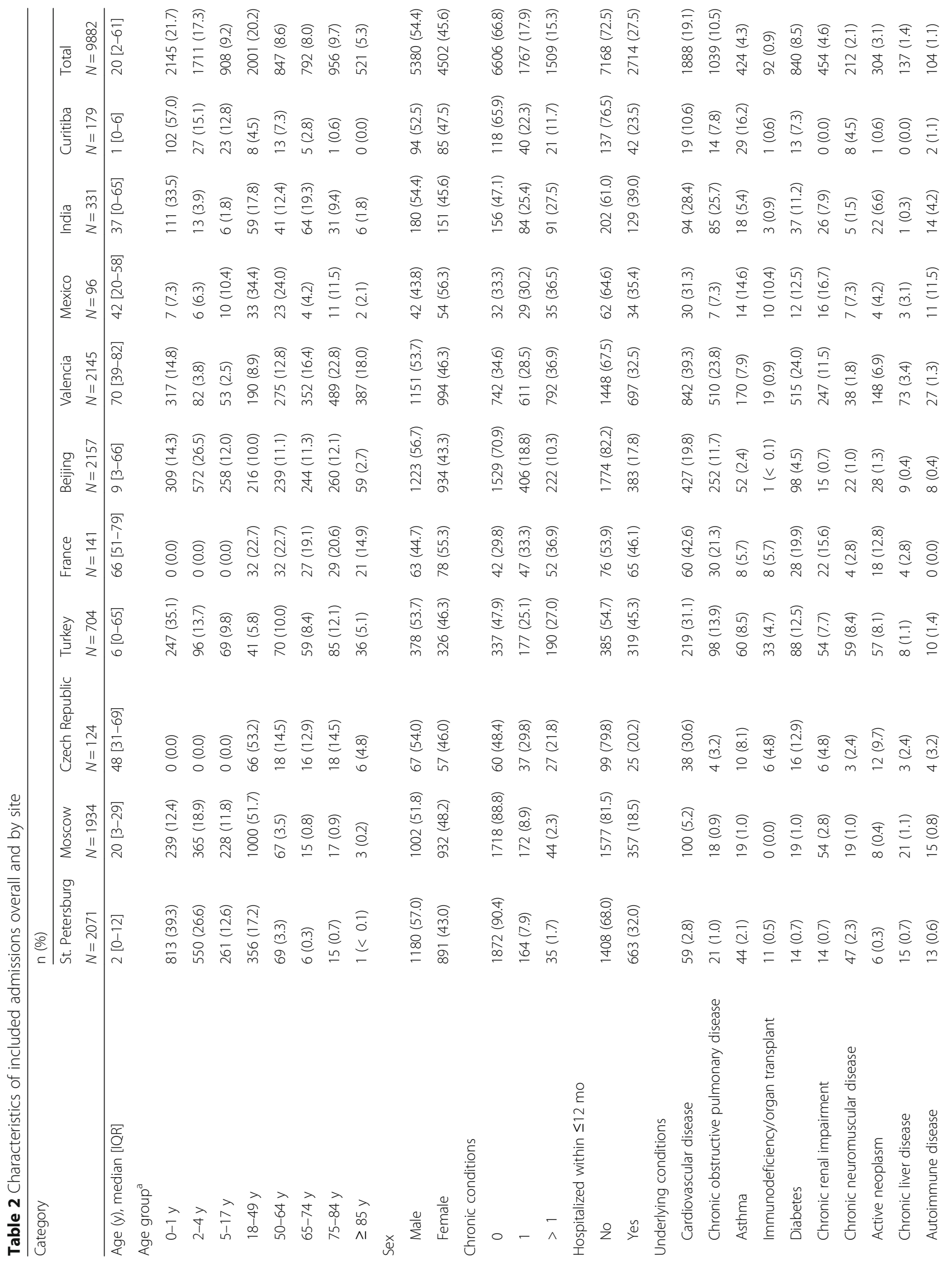




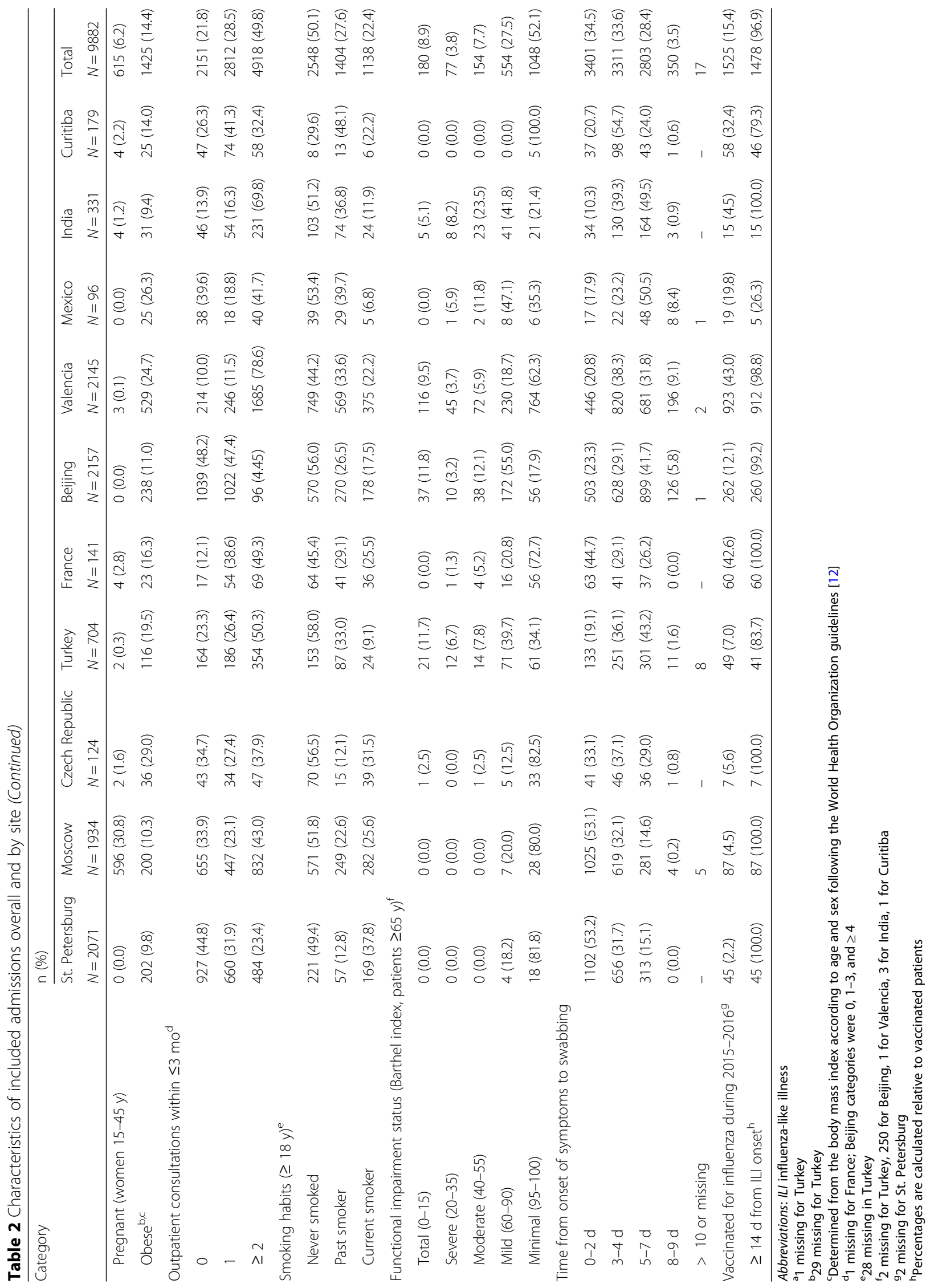


in St. Petersburg. The Czech Republic and France did not recruit subjects < 18 years of age. Patients were mostly young adults (18-49 years of age) in the Czech Republic (53.2\%) and Moscow (51.7\%). By contrast, in Valencia (57.2\%) and France (54.6\%), most included admissions were $\geq 65$ years of age.

Admissions were more frequently males than females at all sites (51.8 to 57.0\%) except France (44.7\%) and Mexico (43.8\%). Proportions of patients without comorbidities were highest in St. Petersburg (90.4\%) and Moscow (88.8\%), followed by Beijing (70.9\%), Curitiba (65.9\%), Czech Republic (48.4\%), Turkey (47.9\%), India (47.1\%), Valencia (34.6\%), Mexico (33.3\%), and France (29.8\%). Cardiovascular disease was the most common chronic condition at all sites except Curitiba, where asthma was the most common (Table 2).

In Moscow, $30.8 \%$ of the included patients were pregnant women. By contrast, at the rest of the sites, pregnant women accounted for $<3 \%$ of the included patients.

The proportion of obese patients was highest in the Czech Republic $(n=36 ; 29.0 \%)$, Mexico $(n=25 ; 26.3 \%)$, and Valencia $(n=529 ; 24.7 \%)$ and lowest in India $(n=31$; 9.4\%), St. Petersburg $(n=202 ; 9.8 \%)$, and Moscow $(n=200$; $10.3 \%)$.

Visits to general practitioners during the 3 months before hospitalization were the least common in Beijing $(n=1118$; $51.8 \%)$, St. Petersburg (1144; 55.3\%), and Mexico $(n=58$; $60.5 \%)$ and the most common in Valencia $(n=1931$; $90.0 \%)$, France $(n=123 ; 87.9 \%)$ and India $(n=285 ; 86.1 \%)$.

The proportion of adult patients who had never smoked ranged from $29.6 \%(n=8)$ in Curitiba to $58.0 \%$ $(n=153)$ in Turkey. The proportion of adult patients that currently smoked ranged from $6.8 \%(\mathrm{n}=5)$ in Mexico to $37.8 \%(n=169)$ in St. Petersburg.

Moderate to total functional impairment in older adults ( $\geq 65$ years of age) was least common in St. Petersburg, Moscow, and Curitiba (0.0\%) and highest in India (36.7\%). Vaccination coverage varied substantially between sites (Table 2). Vaccination coverage rates were (in decreasing order) $43.0 \%(n=923)$ in Valencia, $42.6 \%$ $(n=60)$ in France, 32.4\% $(\mathrm{n}=58)$ in Curitiba, 19.8\% ( $\mathrm{n}=$ $19)$ in Mexico, $12.1 \%(n=262)$ in Beijing, $7.0 \%(n=49)$ in Turkey, $5.6 \%(n=7)$ in the Czech Republic, $4.5 \%$ in India $(n=15)$ and Moscow $(n=87)$, and $2.2 \%(n=45)$ in St. Petersburg. Among vaccinated individuals, the vaccine had been administered $\geq 14$ days before the onset of symptoms to $26.3 \%(\mathrm{n}=5)$ of admissions in Mexico, 79.3\% $(n=46)$ in Curitiba, $83.7 \%(n=41)$ in Turkey, and nearly all admissions (99 to 100\%) at other sites. From the information available, $87 \%$ of vaccinated individuals had received a trivalent inactivated influenza vaccine (data not shown). Almost all of the remaining 13\% also received a trivalent vaccine, based on the vaccines available at each study site (Additional file 3: Table S3).
Admission with influenza according to age and variability by influenza virus

Influenza positivity appeared to be related to age. Admissions positive for influenza were younger than admissions negative for influenza, regardless of having underlying conditions (Fig. 2). More than three-quarters (76.1\%) of influenza-positive admissions were $<50$ years of age (Table 3, Fig. 2). Admissions positive for $\mathrm{A}(\mathrm{H} 1 \mathrm{~N} 1)$ pdm09 were generally younger than admissions negative for influenza, positive for $\mathrm{A}(\mathrm{H} 3 \mathrm{~N} 2)$, or positive for $\mathrm{B} /$ Yamagata-lineage but older than admissions positive for B/Victoria-lineage (Table 3).

Heterogeneity due to strain was assessed considering $\mathrm{A}(\mathrm{H} 1 \mathrm{~N} 1) \mathrm{pdm} 09, \mathrm{~A}(\mathrm{H} 3 \mathrm{~N} 2)$, and $\mathrm{B} /$ Victoria-lineage using the $\mathrm{I}^{2}$ statistic with adjustment for sex, social class according to occupation, comorbidity, influenza vaccination, time to swab, and site. By age, $\mathrm{I}^{2}$ was $0.0 \%$ for admissions $1-4,18-49$, and 65-74 years, $80.5 \%$ for $5-17$ years, $88.8 \%$ for $50-64$ years; $44.1 \%$ for $75-84$ years; and $53.2 \%$ for $\geq 85$ years (Fig. 3 ).

\section{Admission with influenza according to sex and variability by influenza virus}

In general, the sex distribution differed significantly between influenza-positive and influenza-negative admissions (Table 3). The risk of admission with influenza was not heterogeneous by strain after adjusting by age, social class according to occupation, comorbidity, influenza vaccination, time to swab, and site, there was no heterogeneity by strain $\left(\mathrm{I}^{2}=0.0 \%\right.$; data not shown $)$. This was also found when pregnant women were excluded $\left(\mathrm{I}^{2}=0.0 \%\right.$; data not shown $)$.

\section{Admission with influenza according to presence of comorbidity}

Older adults positive for influenza were more likely to have underlying chronic conditions (Fig. 2). However, chronic conditions were reported significantly less frequently for influenza-positive $(28.1 \%)$ than influenza-negative admissions $(34.8 \%)(P<0.001$; Table 3$)$. This was also found after excluding pregnant women (29.6\% for influenza-positive vs. $35.9 \%$ for influenza-negative; $P<0.001$ ) (data not shown).

The adjusted OR for admission with influenza was 1.03 (95\% confidence interval [CI], 0.86 to 1.19 ) for patients with comorbidities. No significant heterogeneity by strain was detected $\left(\mathrm{I}^{2}=37.8 \%\right)$ (Fig. 4 ).

\section{Admission with influenza according to pregnancy}

A total of 1051 women 15-45 years old were included in the study, of whom 615 were pregnant (596 in Moscow, 2 in the Czech Republic, 2 in Turkey, 4 in France, 3 in Valencia, 4 in India, and 4 in Curitiba; Table 2) and 436 were not (156 in St. Petersburg, 5 in Moscow, 25 in the Czech Republic, 20 in Turkey, 15 in France, 95 in Beijing, 69 in Valencia, 17 in Mexico, 31 in India, and 3 in Curitiba; data not shown). The probability of laboratory-confirmed influenza was significantly higher $(P<0.001)$ in included 

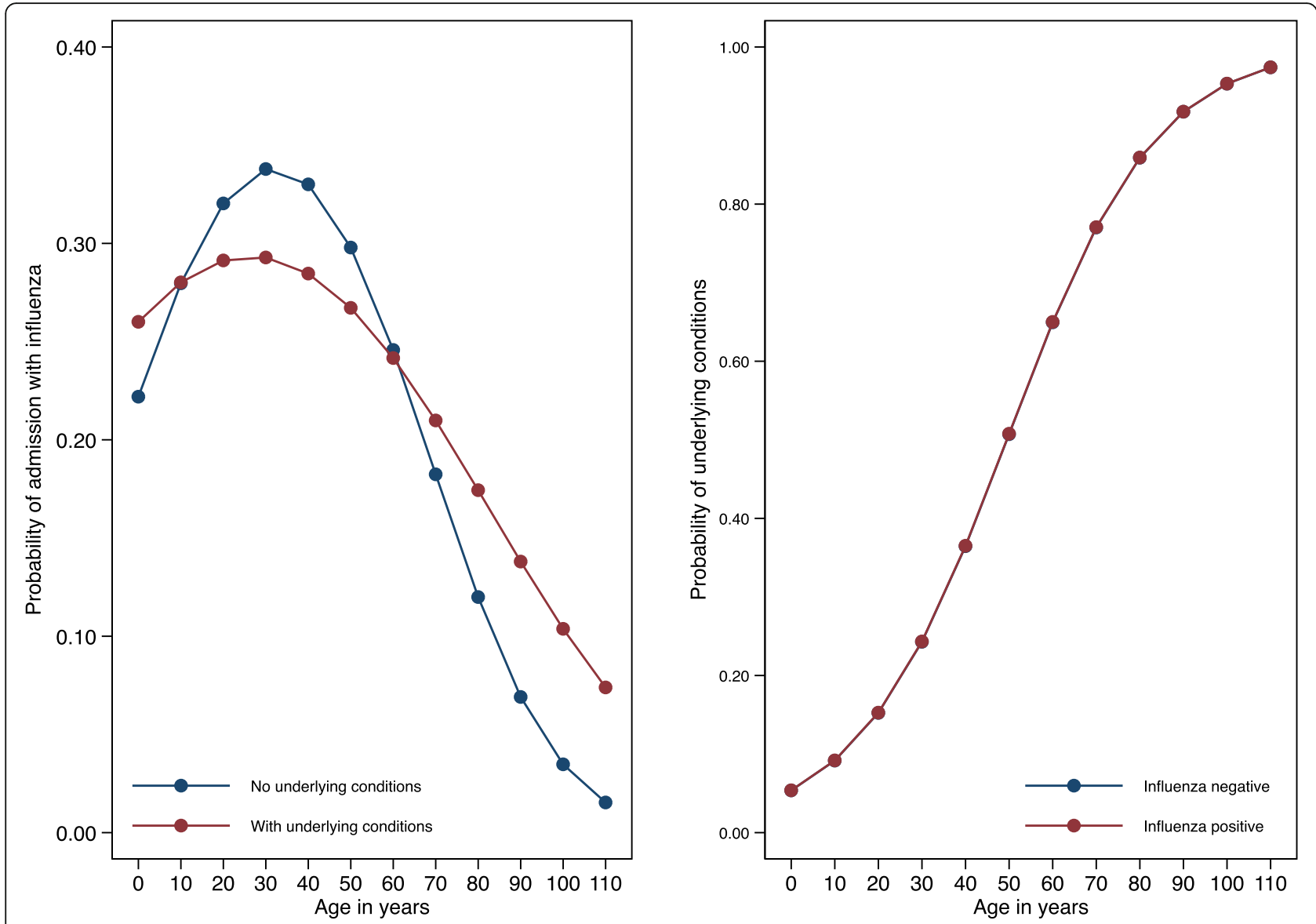

Fig. 2 Admissions with influenza by age and underlying conditions. Adjusted by the interaction of age with chronic conditions, influenza immunization, and site clustering effects

pregnant women $(45.2 \%)$ than non-pregnant women in this age range (23.8\%) (data not shown).

After considering site as a random effect and excluding data from St. Petersburg, Beijing, and Mexico (where no pregnant women were enrolled), the crude OR of admission with influenza was 2.82 (95\% CI, 1.90 to 4.19) for pregnant women (data not shown). When considering pregnant women with no comorbidities, the crude OR was 2.64 (95\% CI, 1.55 to 4.47). For pregnant women with comorbidities, the crude OR was 3.84 (95\% CI, 1.96 to 7.53). There was no evidence of an interaction between comorbidity and pregnancy $(P=0.39)$, but there was evidence of confounding $(P<0.001)$.

The heterogeneity among strains detected in admitted pregnant women was low to moderate $\left(\mathrm{I}^{2}=45.7 \%\right)$. This was due to a higher adjusted OR for admission with $\mathrm{A}(\mathrm{H} 1 \mathrm{~N} 1)$ pdm09 when adjusted for the presence of comorbidities (Fig. 5).

\section{Patients included in the IVE analysis}

Patients with vaccine contraindications (egg allergy or $<6$ months of age) or previous laboratory-confirmed influenza in the same season were excluded from the IVE analysis. After applying these exclusions, 8971 samples obtained from patients hospitalized from December, 2015 to May, 2016 were included. Of these, 2269 (25.3\%) were positive for influenza. By strain, this included 1327 (58.5\%) positive for A(H1N1)pdm09, 511 (22.5\%) for B/Victoria-lineage, 224 (9.9\%) for $\mathrm{A}(\mathrm{H} 3 \mathrm{~N} 2)$, and 41 (1.81\%) for B/Yamagata-lineage (Table 4). Overall, 10.8\% $(n=246)$ of influenza-positive admissions and $18.7 \%(n=1250)$ of influenza-negative admissions were vaccinated $(P<0.001)$ (Table 5$)$.

The proportion of patients vaccinated with the seasonal influenza vaccine $\geq 14$ days before symptom onset was $2.7 \%(n=45)$ in St. Petersburg, $4.6 \%(n=87)$ in Moscow, 5.7\% $(n=7)$ in the Czech Republic, $7.6 \%(n=$ $43)$ in Turkey, $42.6 \%(n=60)$ in France, $12.2 \%(n=258)$ in Beijing, $47.8 \%(n=931)$ in Valencia, $5.4 \%(n=5)$ in Mexico, 5.5\% $(n=15)$ in India, and $34.4 \%(n=45)$ in $\mathrm{Cu}-$ ritiba (data not shown).

Vaccinated admissions were older (median age $=74.8$ years) than unvaccinated admissions (median age $=19.3$ years) $(P<0.001)$ (Table 5$)$. The proportion of participants with underlying conditions was significantly higher 


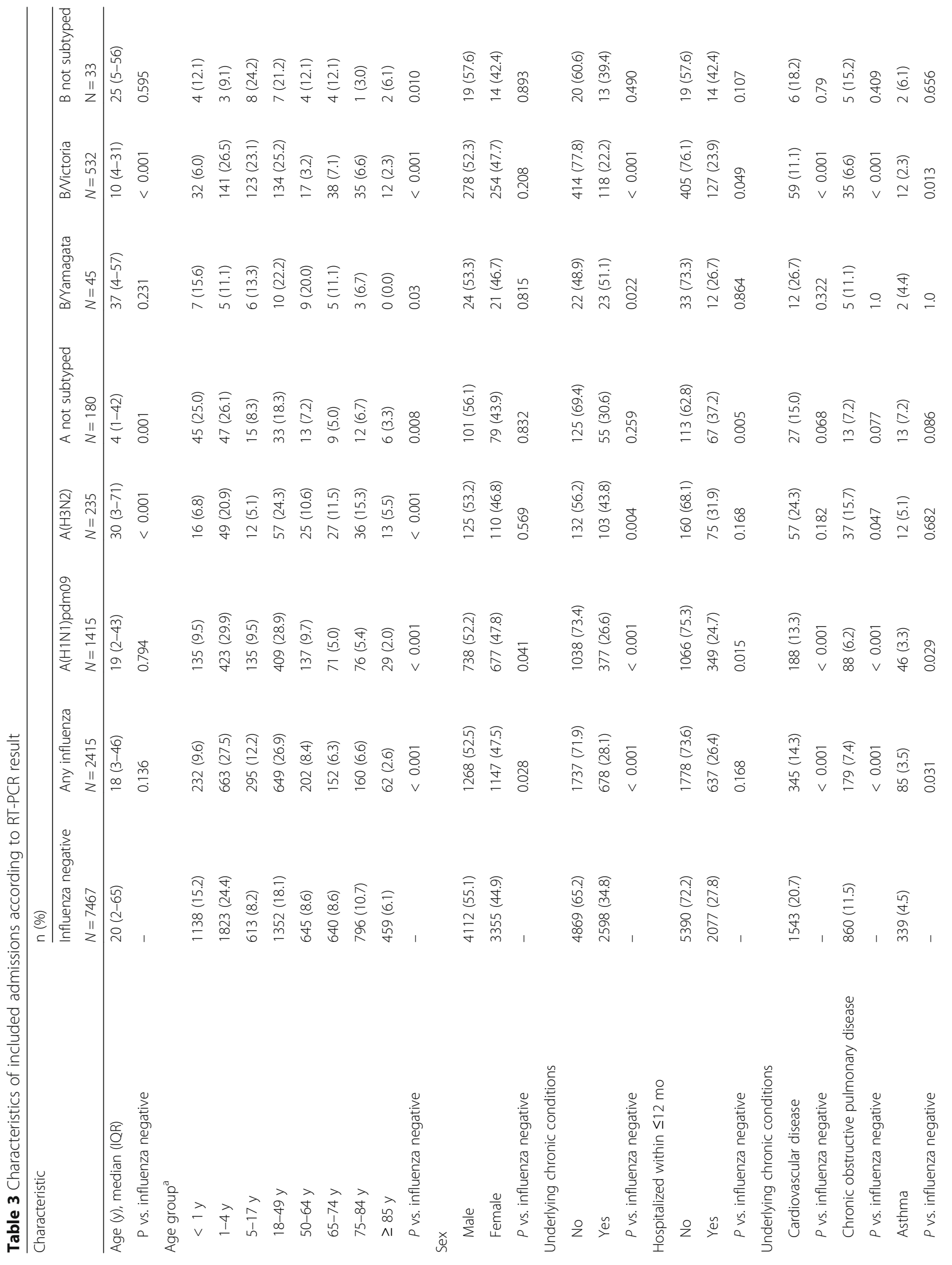




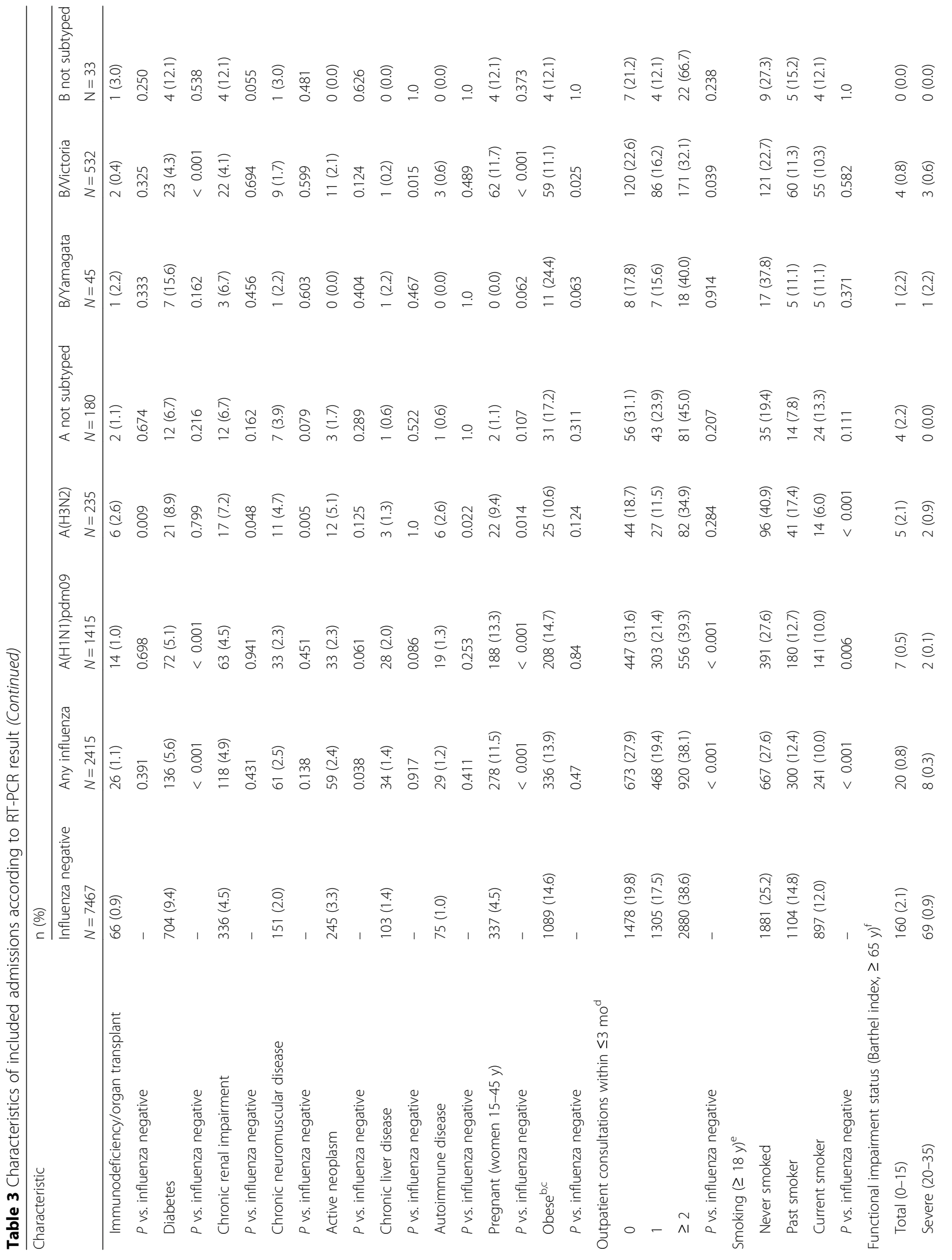




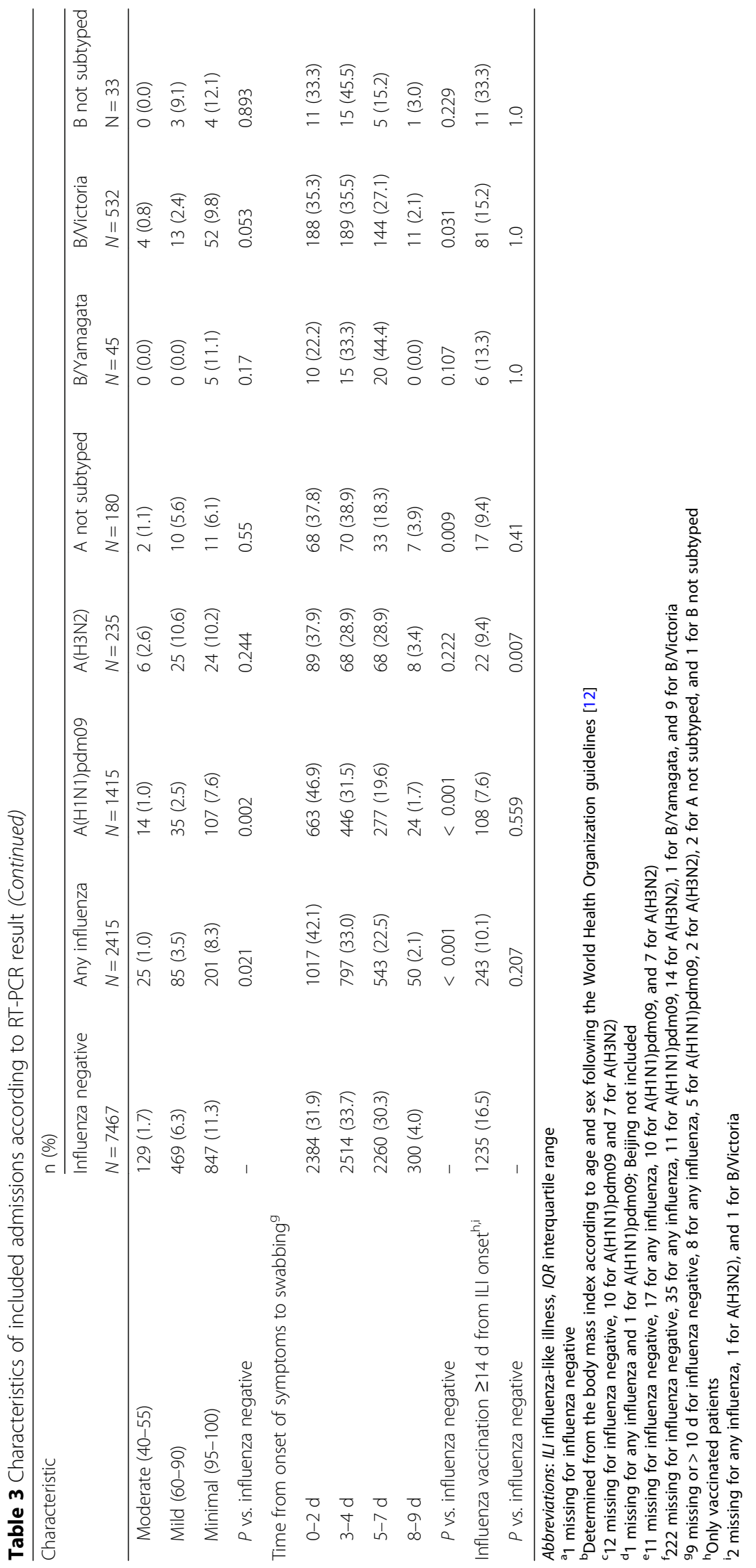




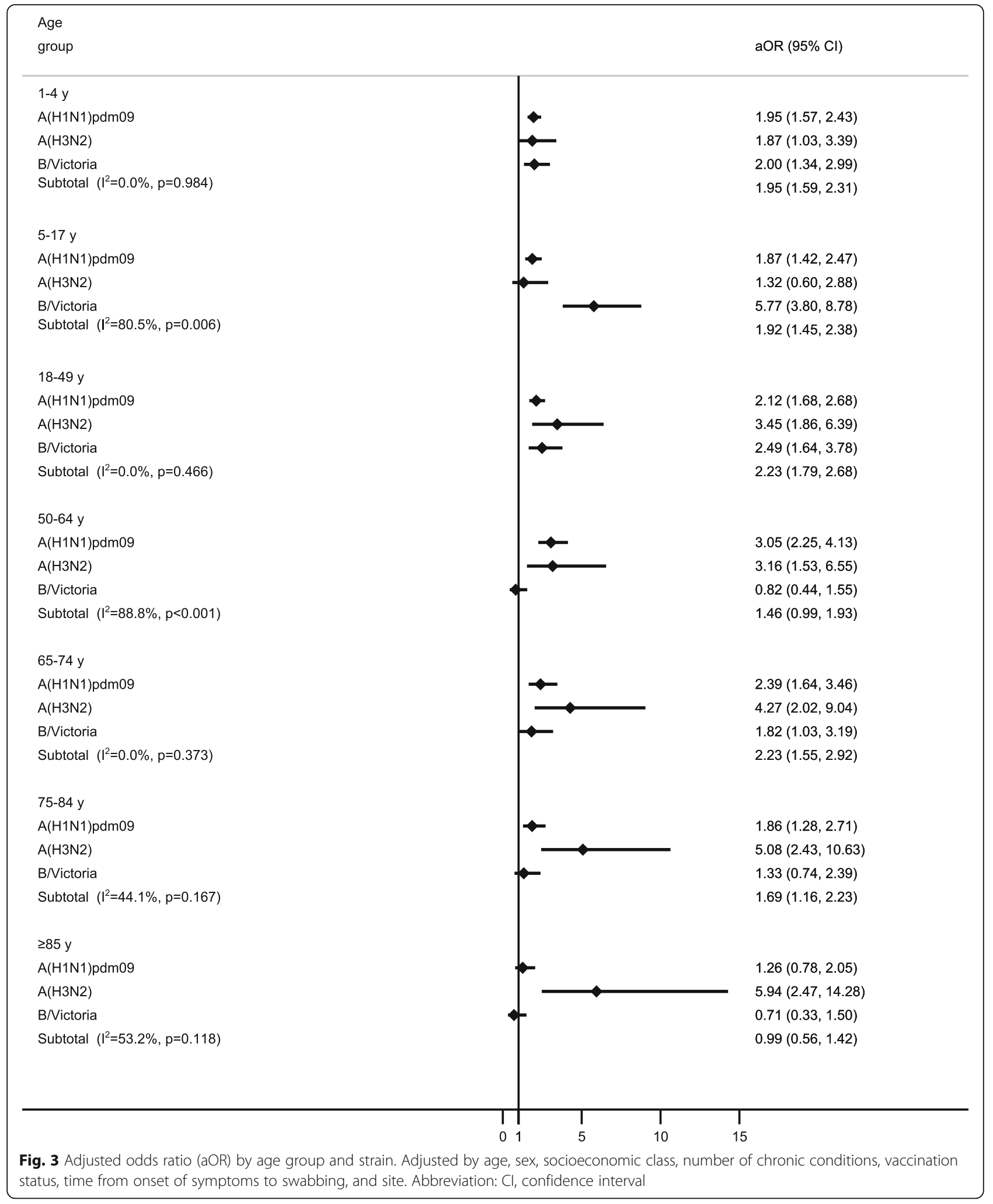

in vaccinated admissions $(72.3 \%)$ than in unvaccinated admissions $(28.4 \%)(P<0.001)$. Also, the proportion of individuals considered obese was higher for vaccinated (21.5\%) than for unvaccinated (13.9\%) admissions $(P<0.001)$. Vaccination was more common in individuals hospitalized in the previous 12 months than in those who had not been 


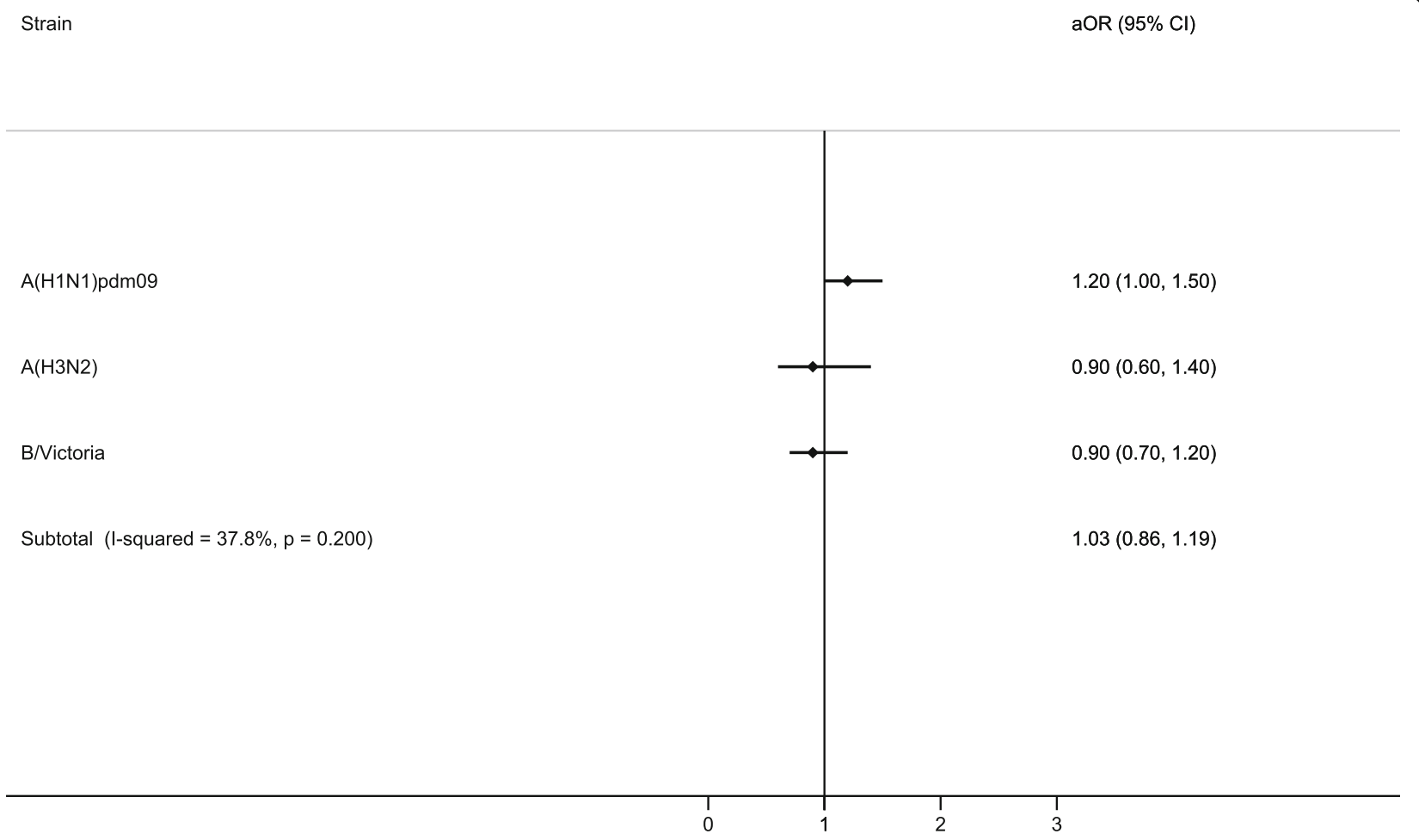

Fig. 4 Adjusted odds ratio (aOR) by strain in admissions with underlying conditions. Adjusted by age, sex, socioeconomic class, obesity status, vaccination status, time from onset of symptoms to swabbing, and site. Abbreviation: $\mathrm{Cl}$, confidence interval

$(P<0.001)$ and more common in individuals who visited a general practitioner within the last 3 months than those who did not $(P<0.001)$. Only 8 of the 614 pregnant patients (1.3\%) were vaccinated. Most patients vaccinated in the 2015-2016 influenza season reported prior influenza vaccination: $72.8 \%$ were also vaccinated in $2013-2014$, and $81.2 \%$ were also vaccinated in 2014-2015.

\section{IVE in overall admissions and in patients targeted for} influenza vaccination

Against all-age influenza-related hospitalization, the crude IVE was $47.0 \%$ (95\% CI, 38.6 to $54.2 \%$ ) overall (Table 4). After adjusting for age, sex, number of chronic conditions, time from onset of symptoms to swabbing, epidemiological week at admission, and site, IVE was

\begin{tabular}{|c|c|}
\hline Strain & aOR $(95 \% \mathrm{Cl})$ \\
\hline $\mathrm{A}(\mathrm{H} 1 \mathrm{~N} 1) \mathrm{pdm} 09$ & $5.47(3.02,9.91)$ \\
\hline $\mathrm{A}(\mathrm{H} 3 \mathrm{~N} 2)$ & $1.62(0.59,4.43)$ \\
\hline BNictoria & $2.34(1.12,4.89)$ \\
\hline Subtotal $\left(l^{2}=45.7 \%, p=0.159\right)$ & $2.45(1.19,3.70)$ \\
\hline
\end{tabular}

Fig. 5 Adjusted odds ratio (aOR) by strain in pregnant admissions 15 to 45 years of age. Adjusted by presence of comorbidities. Only in women aged 15-45 years. Abbreviation: Cl, confidence interval 


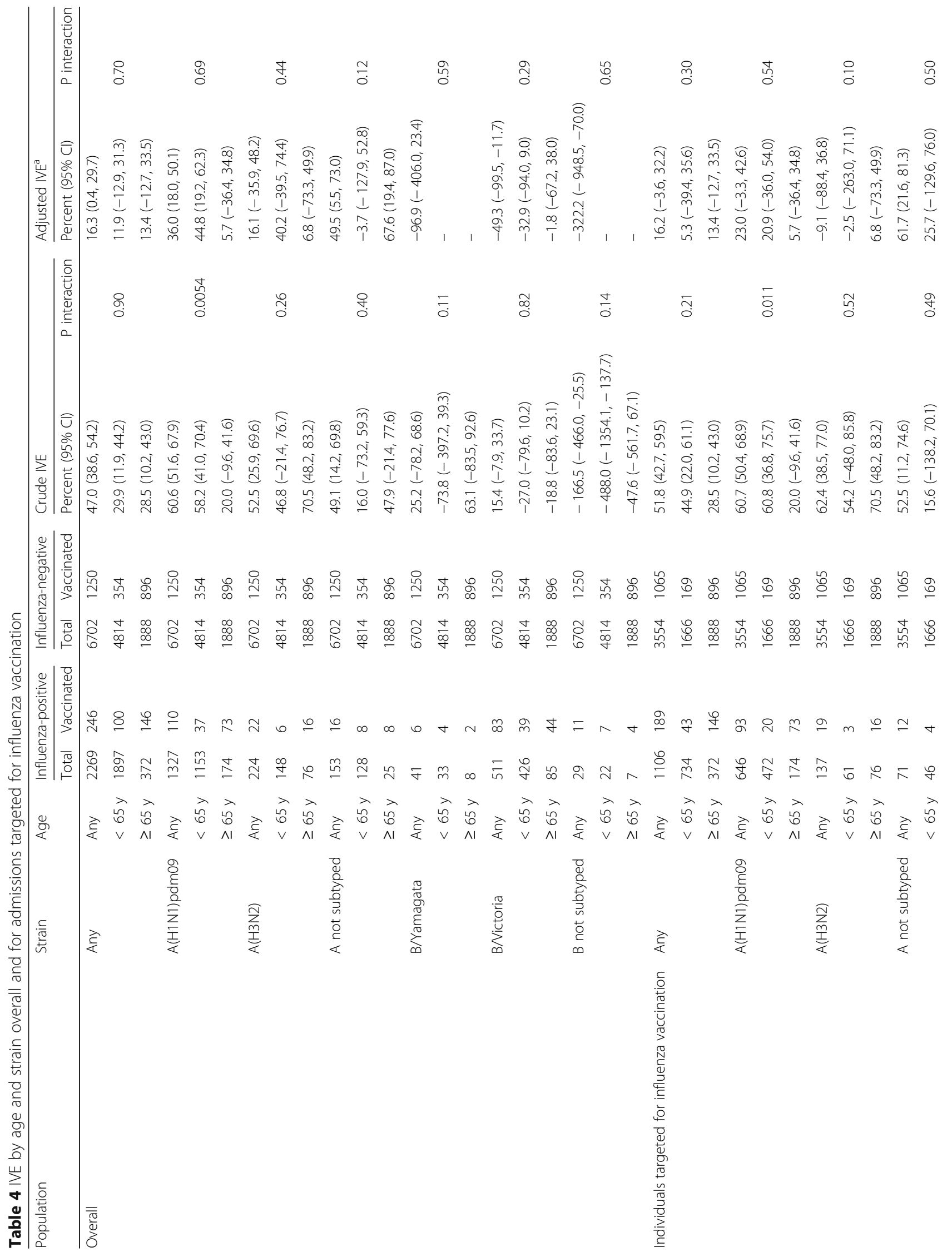




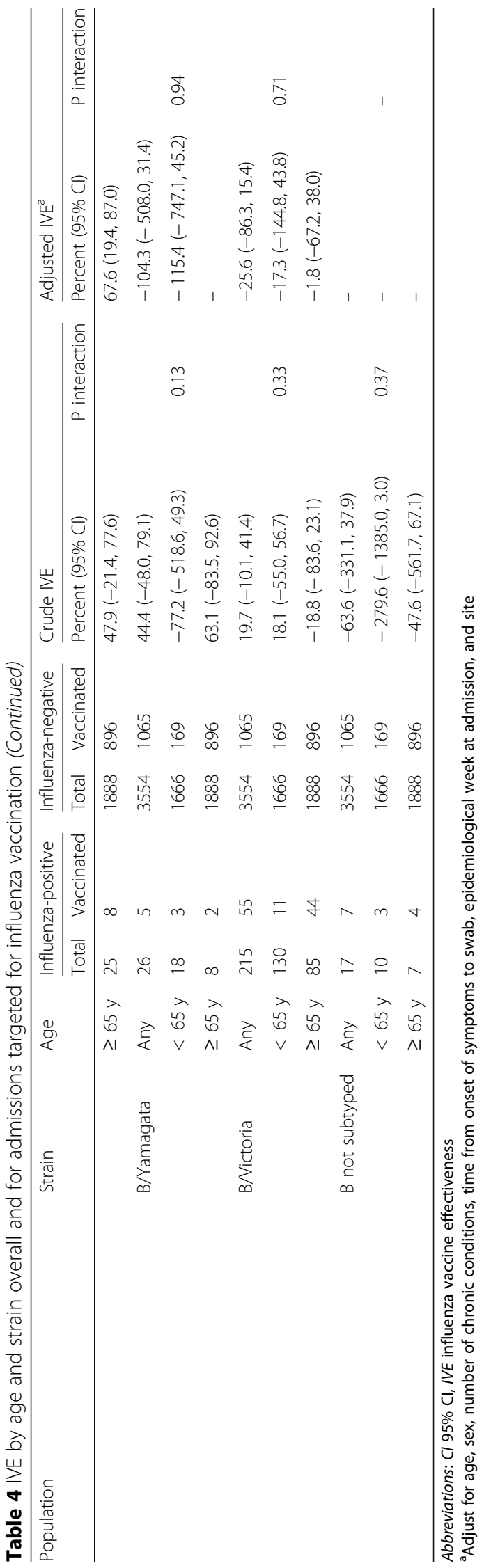


Table $\mathbf{5}$ Characteristics of patients included in the IVE analysis by vaccination status

\begin{tabular}{|c|c|c|c|c|}
\hline Risk variable & Category & Unvaccinated & Vaccinated & $P$ value \\
\hline \multirow[t]{2}{*}{ Number of patients, n (\%) } & Controls & $5452(72.9)$ & $1250(83.6)$ & $<0.001$ \\
\hline & Cases & $2023(27.1)$ & $246(16.4)$ & \\
\hline Age (y) & Median (IQR) & $19.3(3.0-51.9)$ & $74.8(56.3-83.3)$ & $<0.001$ \\
\hline \multirow[t]{8}{*}{ Age group, n (\%) } & 6-11 months & $524(7.0)$ & $14(0.9)$ & $<0.001$ \\
\hline & $1-4 y$ & $2370(31.7)$ & $76(5.1)$ & \\
\hline & $5-17$ y & $758(10.1)$ & $136(9.1)$ & \\
\hline & $18-49$ y & $1879(25.1)$ & $114(7.6)$ & \\
\hline & $50-64$ y & $726(9.7)$ & $114(7.6)$ & \\
\hline & $65-74$ y & $487(6.5)$ & $302(20.2)$ & \\
\hline & $75-84$ y & $513(6.9)$ & $438(29.3)$ & \\
\hline & $\geq 85$ y & $218(2.9)$ & $302(20.2)$ & \\
\hline Female, n (\%) & - & $3480(46.6)$ & $637(42.6)$ & 0.005 \\
\hline \multirow[t]{2}{*}{ Comorbidities, n (\%) } & No & $5350(71.6)$ & $415(27.7)$ & $<0.001$ \\
\hline & Yes & $2125(28.4)$ & $1081(72.3)$ & \\
\hline Pregnant (women 15-45 y), n (\%) & - & $606(59.4)$ & $8(29.6)$ & 0.002 \\
\hline Obese $^{\mathrm{a}}, \mathrm{n}(\%)$ & - & $1038(13.9)$ & $321(21.5)$ & $<0.001$ \\
\hline Hospitalization within $\leq 12$ mo, n (\%) & - & $1954(26.1)$ & $549(36.7)$ & $<0.001$ \\
\hline \multirow[t]{2}{*}{ Outpatient consultations within $\leq 3 \mathrm{mo}, \mathrm{n}(\%)$} & No & $2624(35.11)$ & $304(20.32)$ & $<0.001$ \\
\hline & Yes & $4850(64.89)$ & $1192(79.68)$ & \\
\hline \multirow[t]{3}{*}{ Smoking ( $\geq 18$ y), n (\%) } & Current & $949(25.0)$ & $186(14.7)$ & $<0.001$ \\
\hline & Past & $924(24.3)$ & $475(37.5)$ & \\
\hline & Never & $1926(50.7)$ & $605(47.8)$ & \\
\hline \multirow[t]{5}{*}{ Functional impairment ( $\geq 65$ y), n (\%) } & None or minimal & $471(46.0)$ & $572(58.3)$ & $<0.001$ \\
\hline & Mild & $321(31.4)$ & $232(23.7)$ & \\
\hline & Moderate & $98(9.6)$ & $54(5.5)$ & \\
\hline & Severe & $38(3.7)$ & $39(4.0)$ & \\
\hline & Total & $95(9.3)$ & $84(8.6)$ & \\
\hline Sampling interval (d) & Median (IQR) & $3(2-5)$ & $4(2-5)$ & $<0.001$ \\
\hline \multirow[t]{3}{*}{ Sampling interval, n (\%) } & $\leq 4 \mathrm{~d}$ & $5139(68.8)$ & $920(61.5)$ & \\
\hline & $5-7 d$ & $2104(28.2)$ & $475(31.8)$ & \\
\hline & $8-9 d$ & $232(3.1)$ & $101(6.8)$ & \\
\hline \multirow[t]{10}{*}{ Site, n (\%) } & St. Petersburg & $1645(22.0)$ & $45(3.0)$ & $<0.001$ \\
\hline & Moscow & $1808(24.2)$ & $87(5.8)$ & \\
\hline & Czech Republic & $115(1.5)$ & $7(0.5)$ & \\
\hline & France & $81(1.1)$ & $60(4.0)$ & \\
\hline & Turkey & $522(7.0)$ & $43(2.9)$ & \\
\hline & Beijing & 1854 (24.8) & $258(17.3)$ & \\
\hline & Valencia & 1018 (13.6) & $931(62.2)$ & \\
\hline & India & $259(3.5)$ & $15(1.0)$ & \\
\hline & Mexico & $87(1.2)$ & $5(0.3)$ & \\
\hline & Curitiba & $86(1.2)$ & $45(3.0)$ & \\
\hline \multirow[t]{2}{*}{ Vaccinated, n (\%) } & In 2013-2014 & $526(7.1)$ & $1073(72.8)$ & $<0.001$ \\
\hline & In 2014-2015 & $545(7.4)$ & $1200(81.2)$ & $<0.001$ \\
\hline
\end{tabular}


$16.3 \%$ (95\% CI, 0.4 to $29.7 \%$ ) overall. By strain, the adjusted IVE was $36.0 \%$ (95\% CI, 18.0 to $50.1 \%$ ) against A(H1N1)pdm09, 16.1\% (95\% CI, - 35.9 to $48.2 \%)$ against $\mathrm{A}(\mathrm{H} 3 \mathrm{~N} 2)$ and $-49.3 \%(95 \% \mathrm{CI},-99.5$ to $-11.7 \%)$ against the $\mathrm{B} /$ Victoria-lineage. Considering these three predominant strains, IVE heterogeneity between strains was substantial ( ${ }^{2}$ for adjusted IVE $=84.6 \%$; data not shown). Reliable IVE estimates could not be made by age group for B/Yamagata or B not subtyped because these strains were not frequently detected (Table 4). IVE differed little between younger and older patients in the overall population: the adjusted IVE was $11.9 \%$ (95\% CI, -12.9 to $31.3 \%$ ) for patients < 65 years of age and $13.4 \%$ (95\% CI, - 12.7 to $33.5 \%$ ) for patients $\geq 65$ years of age (Table 4 ). Differences in adjusted IVE between the two age groups for individual strains were not statistically significant.

Results were similar when restricting the analysis to patients targeted for influenza vaccination: the crude IVE for all ages was $51.8 \%$ (95\% CI, 42.7 to $59.5 \%)$ and the adjusted IVE was $16.2 \%$ ( $95 \%$ CI, -3.6 to $32.2 \%$ ) (Table 4). By strain, the adjusted IVE was $23.0 \%$ (95\% CI, - 3.3 to $42.6 \%)$ against $\mathrm{A}(\mathrm{H} 1 \mathrm{~N} 1) \mathrm{pdm} 09,-9.1 \%$ (95\% CI,
-88.4 to $36.8 \%)$ against $\mathrm{A}(\mathrm{H} 3 \mathrm{~N} 2)$, and $-25.6 \%$ (95\% CI, - 86.3 to $15.4 \%$ ) against B/Victoria lineage.

\section{IVE across sites}

The highest overall IVE among all hospitalizations was detected in Moscow, followed by France, St. Petersburg, Turkey, and India (Fig. 6). The lowest IVE was detected in Curitiba, followed by Mexico, Beijing, Czech Republic, and Valencia. IVE was only significant in Moscow. Between sites, heterogeneity in the estimates of IVE against influenza-related hospitalization was low $\left(\mathrm{I}^{2}\right.$ for adjusted IVE $=12.1 \%$ ).

The influenza vaccines available and target populations in each represented country are provided in Additional file 3: Table S3.

\section{Discussion}

Data collected by active surveillance within the GIHSN sites indicated that during the 2015-2016 influenza season (week 48 of 2015 to week 33 of 2016), the predominant circulating strain in hospitalized individuals was $\mathrm{A}(\mathrm{H} 1 \mathrm{~N} 1)$ pdm09 followed by B/Victoria-lineage and

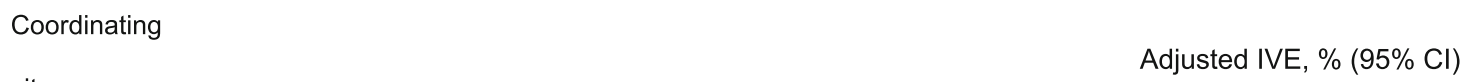

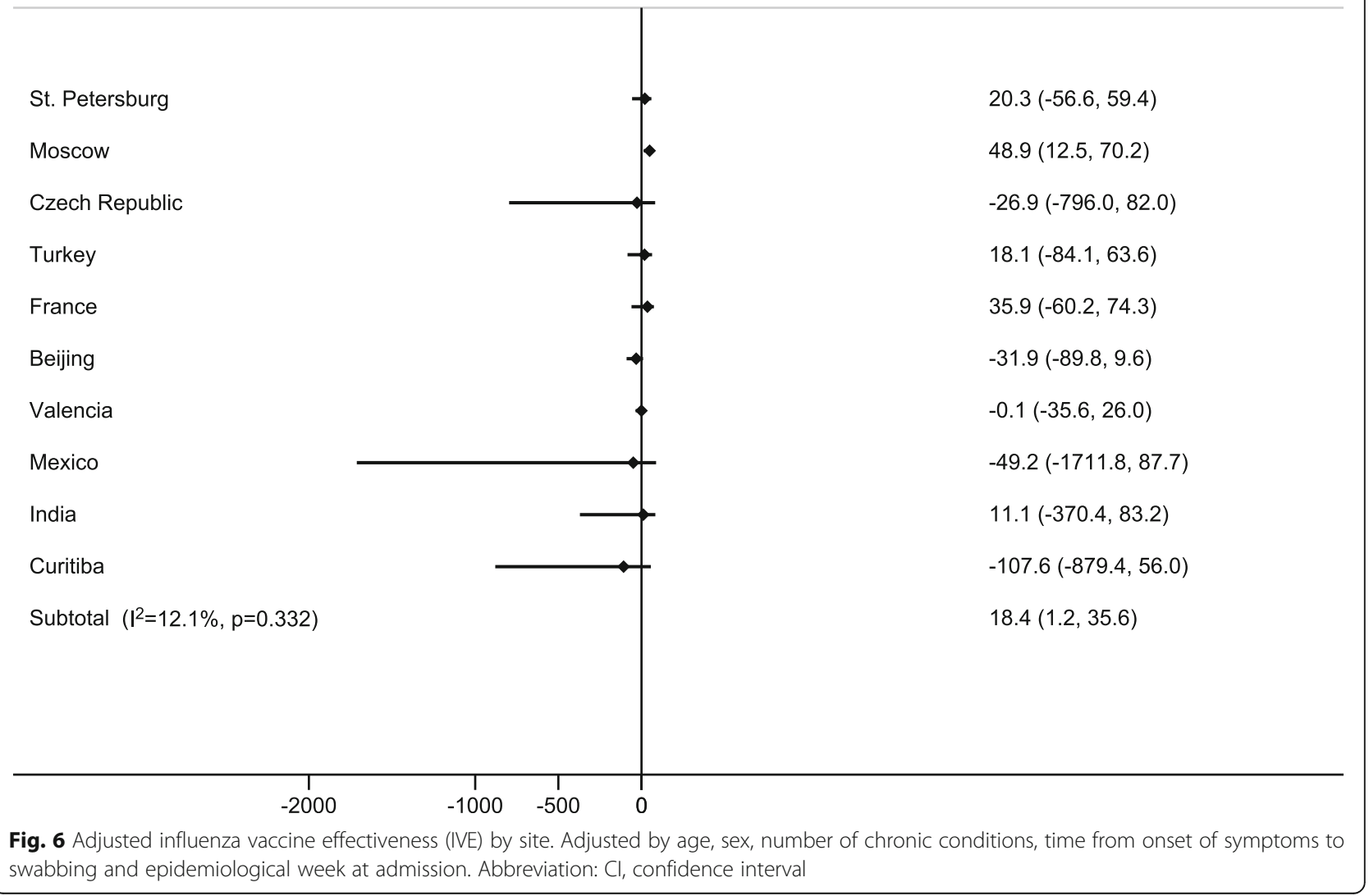


A(H3N2) strains. B/Yamagata-lineage strains were relatively rare. This agrees with overall patterns of influenza circulation reported by the World Health Organization and others [13-17]. The predominance of influenza A(H1N1)pdm09 in Saint Petersburg (Russia), Moscow (Russia), Czech Republic, Turkey, France, Valencia (Spain), Mexico and Curitiba (Brazil), and B/Victoria-lineage in Beijing (China), agree with data reported for these countries [18-24]. Regional activity for A(H3N2) was reported in India, coinciding with our data obtained in the country's Jammu and Kashmir state [24].

During the 2015-2016 season, admissions with laboratoryconfirmed influenza were younger than those who were negative for influenza, and about three-quarters (76\%) of influenza-positive admissions were $<50$ years of age. As found by the GIHSN in 2014-2015 season [8], among patients with laboratory-confirmed influenza, those positive for $\mathrm{A}(\mathrm{H} 1 \mathrm{~N} 1) \mathrm{pdm} 09$ were younger than those positive for $\mathrm{A}(\mathrm{H} 3 \mathrm{~N} 2)$ or $\mathrm{B} /$ Yamagata-lineage, although patients positive for $\mathrm{B} /$ Victoria-lineage were the youngest. Patients with underlying conditions were more prone to be infected by $\mathrm{A}(\mathrm{H} 1 \mathrm{~N} 1) \mathrm{pdm} 09$ or $\mathrm{A}(\mathrm{H} 3 \mathrm{~N} 2)$ than by $\mathrm{B} /$ Victoria-lineage. However, most (72\%) of the influenza-positive patients did not have chronic conditions (Fig. 2). These results confirm that healthy and young individuals are susceptible to severe influenza, in agreement with our previous reports [5-8].

As reported previously in the GIHSN $[7,8]$ and in a recent meta-analysis [25], hospitalized women were more likely to be positive for influenza if they were pregnant. However, only 8 out of 614 (1.3\%) pregnant women were vaccinated against influenza. The vaccination coverage rate was also low for the overall study population (15.4\%).

According to the current study, IVE in 2015-2016 was low to moderate against hospitalization with laboratoryconfirmed influenza (adjusted IVE $=16.3 \%$ [95\% CI, 0.4 to 29.7\%]) and did not differ significantly between younger and older patients. By comparison, the GIHSN reported overall adjusted IVEs against hospitalization with laboratory-confirmed influenza of 33\% (95\% CI, 11 to $49 \%$ ) in $2012-2013$ [5] and $22 \%$ (95\% CI, 8 to $33 \%$ ) in 2014-2015 [8]. Other reports from Hong Kong, the US, and Finland have shown a higher IVE for the 2015-2016 season (IVEs $\sim 50 \%-70 \%$ ) than that reported in the current study [26-29]. We speculate that the differences in IVE estimates are related to a combination of different circumstances; among them, the variable genetic and antigenic characteristics of the $\mathrm{A}(\mathrm{H} 1 \mathrm{~N} 1) \mathrm{pdm} 09$ and $\mathrm{A}(\mathrm{H} 3 \mathrm{~N} 2)$ emerging clades circulating in different parts of the world [30-32], the potential inadequacy of the response to egg-derived vaccines [33], the mismatch between the vaccine and circulating B viruses [34], and the age composition compounded with low levels of vaccination in our population [35].
The highest IVE was against $\mathrm{A}(\mathrm{H} 1 \mathrm{~N} 1) \mathrm{pdm} 09$ (adjusted IVE $=36.0 \%$ [95\% CI, 18.0 to $50.1 \%$ ), in agreement with reports that the circulating $\mathrm{A}(\mathrm{H} 1 \mathrm{~N} 1) \mathrm{pdm} 09$ virus was antigenically similar to the vaccine strain [15]. Despite a new emerging $\mathrm{A}(\mathrm{H} 1 \mathrm{~N} 1)$ pdm09 6B.1 subclade detected in Spain, Canada, and Denmark [30, 31, 36], several other studies have similarly reported moderate effectiveness against $\mathrm{A}(\mathrm{H} 1 \mathrm{~N} 1) \mathrm{pdm} 09$ in different age groups and healthcare settings [26, 28, 31, 36-38].

We were unable to obtain reliable IVE estimates for B/ Yamagata-lineage or B not subtyped by age group because these strains were not frequently detected. The vaccine had no effect on illness caused by B/Victoria-lineage viruses, which could be due to the absence of a $\mathrm{B} /$ Victoria-lineage strain from the WHO-recommended trivalent inactivated vaccine for the northern hemisphere 2015-2016 season [39]. This also suggests that any cross-lineage antibody response from the trivalent vaccine B/Yamagata-lineage strain was insufficient to protect against illness caused by circulating B/Victoria-lineage strains. Although we obtained one isolated negative IVE in preventing admissions with $\mathrm{B} /$ Victoria-lineage, all other IVE estimates for the B/Victoria-lineage consistently showed no effect, and so emphasizing this isolated negative IVE would incorrectly reject the null hypothesis [40]. A multi-comparison adjustment could have been used to solve this, though we choose to follow the reasoning of other authors that endorse the reporting of all results, not adjusting for multiple comparisons [41, 42]. These findings are consistent with several other reports for the 2015-2016 season [27, 36, 43] and highlight the need for quadrivalent vaccines containing both $B$ lineages [44-46].

We observed substantial differences between crude and adjusted IVE estimates. This is likely because young adults have a lower probability of vaccination and underlying conditions compared to older subjects, whereas older adults are more often vaccinated and experience an increased risk of adverse health effects due to age and underlying comorbidities (as shown in Fig. 2). Therefore, when no age distinction is made in the analysis (i.e., no adjustment or stratification by age) this bias leads to a higher vaccination efficacy and, accordingly, the estimate adjusted by age and stratified by age group (i.e., $<65$ and $\geq 65$ years) is lower than the crude (unadjusted, not stratified) estimate. Indeed, some authors consider it improper to report crude estimates at all [47].

\section{Limitations and considerations}

As described previously [7], results from the GIHSN should be interpreted with caution due to the heterogeneity and bias of multi-centric observational studies. The GIHSN takes heterogeneity into account by using a test-negative design that compares laboratory-confirmed influenza admissions with influenza-negative admissions, 
and by restricting the analysis to periods with influenza circulation, adjusting modeling, and accepting only data from patients admitted within 7 days of the onset of ILI symptoms. In addition, all participating sites follow a standardized protocol that is regularly reviewed and reinforced during the GIHSN annual general meeting and on-site visits at each participating hospital. Through this common core protocol, the ILI case definition used in our study was the same between different study sites, and selection bias was minimized by enrolling consecutive admissions without knowing their vaccination status or the laboratory results for influenza infection.

In addition, different sources of data were used to ensure complete case ascertainment, including data from clinical records, health registries, and information provided by the patient and attending nurses and doctors. Influenza vaccination status was obtained by asking the patient (or representative) if they had received the current season's influenza vaccine, the date of vaccination, and if the vaccine had been administered at least 2 weeks before the onset of symptoms. Additionally, when records existed, this information was validated by existing registers, vaccination cards, or through contacting the clinic where the vaccine was administered. To describe heterogeneity we reported the $\mathrm{I}^{2}$ parameter. Finally, we used random effects to account for variability by site.

From 2014-2015 to 2015-2016, the GIHSN expanded from seven coordinating sites in six countries to 11 coordinating sites in nine countries. Even though the GIHSN has expanded, the total number of included admissions decreased slightly from the previous year: in 2015-2016, 18,360 eligible admissions were identified of which 9882 (53.8\%) met the inclusion criteria, whereas in 2014-2015, 23,551 eligible admissions of which 9614 (40.8\%) met the inclusion criteria. Therefore, for some analyses, small numbers continue to be a limitation. The ability to pool data across the GIHSN sites helps, although further improvement will depend on the continued expansion of the network and the growing experience of the participating sites.

\section{Conclusions}

The 2015-2016 influenza season was dominated by $\mathrm{A}(\mathrm{H} 1 \mathrm{N1}$ )pdm09, followed by B/Victoria-lineage and $\mathrm{A}(\mathrm{H} 3 \mathrm{~N} 2)$, with few cases of B/Yamagata-lineage. Many of the influenza hospitalizations were for young, otherwise healthy individuals, and as in previous years, hospitalized women were more likely to be positive for influenza if they were pregnant. During the 2015-2016 season, influenza vaccines provided low to moderate protection against hospitalization with influenza and no protection against the predominant circulating B lineage, highlighting the need for more effective and broader influenza vaccines.

\section{Additional files}

Additional file 1: Table S1. Signs and symptoms required for
enrollment in patients less than five years of age. (DOCX $17 \mathrm{~kb}$ )

Additional file 2: Table S2. Time periods of patient enrolment for each study site. (DOCX $17 \mathrm{~kb}$ )

Additional file 3: Table S3. Vaccines available and targeted groups for vaccination in the GIHSN participating sites. (DOC $48 \mathrm{~kb}$ )

\author{
Abbreviations \\ Cl: Confidence interval; GIHSN: Global Influenza Hospital Surveillance \\ Network; ILI: Influenza-like illness; IVE: Influenza vaccine effectiveness; \\ OR: Odds ratio
}

\section{Acknowledgements}

Medical editing was provided by Drs. Phillip Leventhal and Jonathan Pitt (4Clinics, Paris, France) and paid for by Sanofi Pasteur.

The GIHSN members include: O. Afanasieva, Research Institute of Influenza, St. Petersburg, Russian Federation; M. Akcay Ciblak, Sanofi Pasteur, Istanbul, Turkey; A. Bagci Bosi, Hacettepe University, Faculty of Medicine, Ankara, Turkey; V. Baselga-Moreno, FISABIO-Public Health, Valencia, Spain; E. Burtseva, D.I. Ivanovsky Institute of Virology FSBI "N.F. Gamaleya NRCEM", Moscow, Russian Federation; M. Carballido-Fernández, Hospital General de Castellón, Castellón, Spain; P. Cervantes, Sanofi Pasteur, France; B. Costa-Caetano,

Foundation Oswaldo Cruz Foundation (FIOCRUZ), Rio de Janeiro, Brazil; B. Cowling, School of Public Health, Li Ka Shing Faculty of Medicine, University of Hong Kong, Hong Kong Special Administrative Region, China; M. de los Ángeles-Gutiérrez, Sanofi Pasteur, Mexico; J. Díez-Domingo, FISABIO-Public Health, Valencia, Spain; M. Durusu Tanriover, Turkish Society of Internal Medicine, Ankara, Turkey; C. El Guerche-Seblain, Sanofi Pasteur, Lyon, France; A. Goldstein, Sanofi Pasteur, Moscow, Russia Federation; M.L. Guerrero-Almeida, Instituto Nacional de Ciencias Médicas y Nutrición Salvador Zubirán, Departamento de Infectología, México; B. Guglieri-López, FISABIO-Public Health, Valencia, Spain; J. Gurlichova, Sanofi Pasteur, Lyon, France; Y. Hongjie, Key Laboratory of Surveillance and Early-warning on Infectious Disease, Division of Infectious Disease, Chinese Center for Disease Control and Prevention, Beijing, China; L. Kisteneva, D.I. Ivanovsky Institute of Virology FSBI "N.F. Gamaleya NRCEM", Moscow, Russian Federation; L. Kolobukhina, D.I. Ivanovsky Institute of Virology FSBI "N.F. Gamaleya NRCEM", Moscow, Russian Federation; P. Koul, Department of Internal and Pulmonary Medicine, Sher-iKashmir Institute of Medical Sciences (SKIMS), Soura, Srinagar, Jammu \& Kashmir, India; J. Kyncl, National Institute of Public Health, Prague, Czech Republic; O. Launay, INSERM, Réseau National d'Investigation Clinique en Vaccinologie (I-REIVAC), Université Paris Descartes, Sorbonne Paris Cité, and Assistance Publique Hôpitaux de Paris, Hôpital Cochin, Paris, France; Z. Lesieur, INSERM, Réseau National d'Investigation Clinique en Vaccinologie (I-REIVAC), Paris, France; F.X. López-Labrador, FISABIO-Public Health, Valencia, Spain; P. Loulergue, Hôpital Cochin, Paris, France; F. Luzhao, Key Laboratory of Surveillance and Early-warning on Infectious Disease, Division of Infectious Disease, Chinese Center for Disease Control and Prevention, Beijing, China; C. Mahé, Sanofi Pasteur, Lyon, France; Z. Mandakova, National Institute of Public Health, Prague, Czech Republic; A. Mira-Iglesias, FISABIO-Public Health, Valencia, Spain; J. Mollar-Maseres, Hospital Universitario y Politécnico La Fe, Valencia, Spain; F.E. Moura, Universidade Federal do Ceará, Fortaleza, Brazil; K. Mubashir, Department of Internal and Pulmonary Medicine, Sher-i-Kashmir Institute of Medical Sciences (SKIMS), Soura, Srinagar, Jammu \& Kashmir, India; W. Peng, School of Public Health, Li Ka Shing Faculty of Medicine, University of Hong Kong, Hong Kong Special Administrative Region, China; V. Picot, Fondation Mérieux, Lyon, France; M. Pisareva, Research Institute of Influenza, St. Petersburg, Russian Federation; F. Pradel, Fondation Mérieux, Lyon, France; J. Puig-Barberà, FISABIO-Public Health, Valencia, Spain; Y Qin, Key Laboratory of Surveillance and Early-warning on Infectious Disease, Division of Infectious Disease, Chinese Center for Disease Control and Prevention, Beijing, China; S. Raboni, Hospital de Clínicas / Universidade Federal do Paraná, Curitiba, Brazil; G.M. Ruiz-Palacios, FIDSA, Director, Comisión Coordinadora de los Institutos Nacionales de Salud y Hospitales de Alta Especialidad, Secretaría de Salud, México; H. Schwarz-Chávarri, Hospital General de Alicante, Alicante, Spain; M. Siqueira, Oswaldo Cruz Foundation (FIOCRUZ), Rio de Janeiro, Brazil; A. Sominina, Research Institute of Influenza, St. Petersburg, Russian Federation; K. 
Stolyarov, Research Institute of Influenza, St. Petersburg, Russian Federation; M. Tortajada-Girbés, Hospital Universitario Doctor Peset, Valencia, Spain; S. Trushakova, D.I. Ivanovsky Institute of Virology FSBI "N.F. Gamaleya NRCEM", Moscow, Russian Federation; S. Unal, Turkish Society of Internal Medicine, Ankara, Turkey; and C. Vlasich, Sanofi Pasteur, France

\section{Funding}

This study was funded by the local coordinating institutions at each site with additional catalytic funding support provided from the Fondation pour I'Epidemiologie de la Grippe. FISABIO received additional funding from the Fondation pour l'Epidemiologie de la Grippe to coordinate the study. The Fondation pour l'Epidemiologie de la Grippe did not participate in the design, conduct of the research, analysis, or decision to publish the study.

\section{Availability of data and materials}

The datasets used and/or analyzed during the current study available from the corresponding author on reasonable request.

\section{Authors' contributions}

JPB and AMI performed the statistical analysis and wrote the manuscript draft. EB, BJC, US, GMRP, OL, JK, PK, MWS and AS made substantial contributions to conception and design, acquisition of data and interpretation of data. EB, BJC, US, GMRP, OL, JK, PK, MWS and AS revised the manuscript for important intellectual content. JPB, AMI, EB, BJC, US, GMRP, $\mathrm{OL}, \mathrm{JK}, \mathrm{PK}, \mathrm{MWS}$ and AS gave final approval of the version to be published and agreed to be accountable for all aspects of the work.

\section{Ethics approval and consent to participate}

The GIHSN study protocol was approved by the institutional review board of each participating site: in India, the Institutional Ethics Committee of the Sher-i-Kashmir Institute of Medical Sciences, Srinagar; in Beijing, China, "The Institutional Review Board of the University of Hong Kong/Hospital Authority Hong Kong West Cluster"; in France, "CPP Ile de France IV, Saint-Louis hospital in Paris"; in the Czech Republic, the "Ethics Committee of the Hospital Na Bulovce"; in Turkey, the "Hacettepe University Non-interventional Clinical Research Ethics Board"; in Moscow, Russia, "The local Ethic Committee of Hospital \#1 for Infectious Diseases of Moscow Health Department"; in Brazil (Fortaleza \& Curitiba), the "Ethical Committee of the Evandro Chagas National Institute of Infectology (INI-Fiocruz)"; in Mexico, the "Research Ethics Committee of the National Institute of Medical Science and Nutrition Salvador Zubirán" \& "Research Committee of the National Institute of Medical Science and Nutrition Salvador Zubirán"; in St Petersburg, Russia, "Local Ethical Committee under the FGBU 'Research Institute of Influenza' of the Ministry of Health of the Russian Federation"; and in Spain, the "Research Ethics Committee of the General Directorate of Public Health and High Center for Public Health Research (CEI DGSP-CSISP)". All subjects or legal representatives provided written or (if approved by the associated institutional review board) oral informed consent; consent to participate was collected from the parents/guardians of any participants under 16 years of age.

\section{Consent for publication}

Not applicable.

\section{Competing interests}

BJC received grants from Sanofi Pasteur unrelated to the submitted work. PK has served as a consultant to Sanofi, Zydus, and Cadila. All other authors declare no competing interests.

\section{Publisher's Note}

Springer Nature remains neutral with regard to jurisdictional claims in published maps and institutional affiliations.

\section{Author details}

${ }^{1}$ Fundación para el Fomento de la Investigación Sanitaria y Biomédica de la Comunidad Valenciana, FISABIO, Valencia, Spain. ${ }^{2}$ Ivanovsky Institute of Virology FSBI "N.F, Gamaleya NRCEM" Ministry of Health, Moscow, Russian Federation. ${ }^{3}$ School of Public Health, Li Ka Shing Faculty of Medicine, Hong Kong, Hong Kong, Special Administrative Region of China. ${ }^{4}$ Turkish Society of Internal Medicine, Ankara, Turkey. ${ }^{5}$ Salvador Zubirán National Institute of Medical Sciences and Nutrition (INCMNSZ), Vasco de Quiroga 15, Belisario Domínguez Sección 16, 14080 Tlalpan, CDMX, Mexico. ' INSERM, F-CRIN,
Réseau National d'Investigation Clinique en Vaccinologie (I-REIVAC), CIC Cochin Pasteur, Paris, France and Université Paris Descartes, Sorbonne Paris Cité and Assistance Publique Hôpitaux de Paris, Hôpital Cochin, Paris, France. ${ }^{7}$ National Institute of Public Health, Prague, Czech Republic. ${ }^{8}$ Department of Internal and Pulmonary Medicine, Sher-i-Kashmir Institute of Medical Sciences (SKIMS), Soura, Bemina, Srinagar, Jammu \& Kashmir 190011, India. ${ }^{9}$ FIOCRUZ, Rio de Janeiro, Brazil. ${ }^{10}$ Research Institute of Influenza, WHO National Influenza Centre of Russia and Ministry of Healthcare of the Russian Federation, St. Petersburg, Russian Federation.

\section{Received: 13 December 2018 Accepted: 24 April 2019}

Published online: 14 May 2019

\section{References}

1. Puig-Barbera J, Tormos A, Trushakova S, Sominina A, Pisareva M, Ciblak MA, et al. The Global Influenza Hospital Surveillance Network (GIHSN): a new platform to describe the epidemiology of severe influenza. Influenza Other Respir Viruses. 2015;9(6):277-86. https://doi.org/10.1111/irv.12335.

2. Brammer L, Budd A, Cox N. Seasonal and pandemic influenza surveillance considerations for constructing multicomponent systems. Influenza Other Respir Viruses. 2009;3(2):51-8.

3. Lynfield R, Davey R, Dwyer DE, Losso MH, Wentworth D, Cozzi-Lepri A, et al. Outcomes of influenza a(H1N1)pdm09 virus infection: results from two international cohort studies. PLoS One. 2014;9(7):e101785.

4. Mertz D, Kim TH, Johnstone J, Lam PP, Science M, Kuster SP, et al. Populations at risk for severe or complicated influenza illness: systematic review and meta-analysis. BMJ. 2013;347:f5061

5. Puig-Barbera J, Natividad-Sancho A, Launay O, Burtseva E, Ciblak MA, Tormos A, et al. 2012-2013 seasonal influenza vaccine effectiveness against influenza hospitalizations: results from the Global Influenza Hospital Surveillance Network. PLoS One. 2014;9(6):e100497.

6. Puig-Barbera J, Tormos A, Sominina A, Burtseva E, Launay O, Ciblak MA, et al. First-year results of the Global Influenza Hospital Surveillance Network: 2012-2013 northern hemisphere influenza season. BMC Public Health. 2014; 14:564.

7. Puig-Barbera J, Natividad-Sancho A, Trushakova S, Sominina A, Pisareva M, Ciblak MA, et al. Epidemiology of hospital admissions with influenza during the 2013/2014 northern hemisphere influenza season: results from the Global Influenza Hospital Surveillance Network. PLoS One. 2016;11(5): e0154970.

8. Puig-Barbera J, Burtseva E, Yu H, Cowling BJ, Badur S, Kyncl J, et al. Influenza epidemiology and influenza vaccine effectiveness during the 2014-2015 season: annual report from the Global Influenza Hospital Surveillance Network. BMC Public Health. 2016;16(Suppl 1):757.

9. European Centre for Disease Prevention and Control. Influenza case definitions. 2005-2017. https://eur-lex.europa.eu/legal-content/EN/TXT/PDF/ ?uri=CELEX:32018D0945\&from=EN\#page=24. Accessed 2 Nov 2012.

10. Kohler U, Kreuter F. Conditional-effects plots. In: Data analysis using Stata. 3rd ed. College Station: Stata press; 2012. p. 321-4.

11. Motulsky HCA. Fitting models to biological data using linear and nonlinear regression: a practical guide to curve fitting. New York: Oxford University Press; 2004.

12. World Health Organization. Obesity: preventing and managing the global epidemic. Geneva: Report of a WHO consulation; 2000.

13. World Health Organization. Review of global influenza activity, October 2015-October 2016. Wkly Epidemiol Rec. 2016;91(51-52):604-22.

14. Cieslak K, Szymanski K, Kowalczyk D, Brydak LB. Influenza and influenza-like viruses in children in the epidemic season 2015/2016 in Poland. Adv Exp Med Biol. 2017:968:13-8.

15. Korsun N, Angelova S, Gregory V, Daniels R, Georgieva I, McCauley J. Antigenic and genetic characterization of influenza viruses circulating in Bulgaria during the 2015/2016 season. Infect Genet Evol. 2017;49:241-50.

16. Kowalczyk D, Cieslak K, Szymanski K, Brydak LB. The activity of influenza and influenza-like viruses in individuals aged over 14 in the 2015/2016 influenza season in Poland. Adv Exp Med Biol. 2017;980:45-50.

17. Davlin SL, Blanton L, Kniss K, Mustaquim D, Smith S, Kramer N, et al. Influenza activity - United States, 2015-16 season and composition of the 2016-17 influenza vaccine. MMWR Morb Mortal Wkly Rep. 2016; 65(22):567-75.

18. Gherasim A, Martinez-Baz I, Castilla J, Pozo F, Larrauri A. Effect of previous and current vaccination against influenza a(H1N1)pdm09, a(H3N2), and $B$ 
during the post-pandemic period 2010-2016 in Spain. PLoS One. 2017;12(6): e0179160.

19. Lvov DK, Kolobukhina LV, Burtseva El, Kruzhkova IS, Malyshev NA, Fedyakina IT, et al. The 2015-2016 epidemic season in Russia and the world: circulation of influenza viruses, trends in incidence, clinical aspects, and treatment algorithm. Ter Arkh. 2016;88(11):112-20.

20. Ruiz-Matus $C$, Kuri-Morales $P$, Narro-Robles J. Behavior of influenza seasons in Mexico from 2010 to 2016: analysis and prospective. Gac Med Mex. 2017; 153(2):205-13

21. Tanriover MD, Bagci Bosi T, Ozisik L, Bilgin E, Guzel Tunccan O, Ozgen O, et al. Poor outcomes among elderly patients hospitalized for influenza-like illness. Curr Med Res Opin. 2018;34(7):1201-7.

22. Janin H. La grippe durant l'épidémie 2015-2016: caractère tardif, gravité clinique et émergence du virus B Victoria. Médecine humaine et pathologie. 2017. https://dumas.ccsd.cnrs.fr/dumas-01611698/document.

23. Zhang L, Pan Y, Hackert V, van der Hoek W, Meijer A, Krafft T, et al. The 2015-2016 influenza epidemic in Beijing, China: unlike elsewhere, circulation of influenza a(H3N2) with moderate vaccine effectiveness. Vaccine. 2018; 36(33):4993-5001.

24. World Health Organization. Recommended composition of influenza virus vaccines for use in the 2017 southern hemisphere influenza season. Wkly Epidemiol Rec. 2016;91(41):469-84.

25. Mertz D, Geraci J, Winkup J, Gessner BD, Ortiz JR, Loeb M. Pregnancy as a risk factor for severe outcomes from influenza virus infection: a systematic review and meta-analysis of observational studies. Vaccine. 2017;35(4):521-8.

26. Jackson ML, Chung JR, Jackson LA, Phillips CH, Benoit J, Monto AS, et al. Influenza vaccine effectiveness in the United States during the 2015-2016 season. N Engl J Med. 2017;377(6):534-43.

27. Nohynek H, Baum U, Syrjanen R, Ikonen N, Sundman J, Jokinen J. Effectiveness of the live attenuated and the inactivated influenza vaccine in two-year-olds - a nationwide cohort study Finland, influenza season 2015/ 16. Euro Surveill. 2016;21(38):1-8.

28. Poehling KA, Caspard H, Peters TR, Belongia EA, Congeni B, Gaglani M, et al. 2015-2016 vaccine effectiveness of live attenuated and inactivated influenza vaccines in children in the United States. Clin Infect Dis. 2018;66(5):665-72.

29. Yeung KHT, Chan KCC, Chan PKS, Lam DSY, Sham PCO, Yau YS, et al. Influenza vaccine effectiveness in hospitalised Hong Kong children: feasibility of estimates from routine surveillance data. Vaccine. 2018:36(24):3477-85.

30. Puig-Barbera J, Guglieri-Lopez B, Tortajada-Girbes M, Lopez-Labrador FX, Carballido-Fernandez M, Mollar-Maseres J, et al. Low influenza vaccine effectiveness and the effect of previous vaccination in preventing admission with a(H1N1)pdm09 or B/Nictoria-lineage in patients 60 years old or older during the 2015/2016 influenza season. Vaccine. 2017;35(52):7331-8.

31. Skowronski DM, Chambers C, Sabaiduc S, De Serres G, Winter AL, Dickinson $J A$, et al. Beyond antigenic match: possible agent-host and immunoepidemiological influences on influenza vaccine effectiveness during the 2015-2016 season in Canada. J Infect Dis. 2017;216(12):1487-500.

32. Rothman KJ, Greenland S, Lash TL. Validity in epidemiological studies. In: Modern epidemiology. Philadelphia: Wolters Kluwer Health/Lippincott Williams \& Wilkins; 2008. p. 128-47.

33. Zost SJ, Parkhouse K, Gumina ME, Kim K, Diaz Perez S, Wilson PC, et al. Contemporary H3N2 influenza viruses have a glycosylation site that alters binding of antibodies elicited by egg-adapted vaccine strains. Proc Natl Acad Sci U S A. 2017;114(47):12578-83.

34. World Health Organization. Review of the 2015 influenza season in the southern hemisphere. Wkly Epidemiol Rec. 2015;90(48):645-60.

35. Skowronski DM, Chambers C, De Serres G, Sabaiduc S, Winter AL, Dickinson $J A$, et al. Age-related differences in influenza B infection by lineage in a community-based sentinel system, 2010-2011 to 2015-2016, Canada. J Infect Dis. 2017;216(6):697-702.

36. Emborg HD, Krause TG, Nielsen L, Thomsen MK, Christiansen CB, Skov MN, et al. Influenza vaccine effectiveness in adults 65 years and older, Denmark, 2015/16 - a rapid epidemiological and virological assessment. Euro Surveill. 2016;21(14):1-6

37. Kissling E, Valenciano M, Pozo F, Vilcu AM, Reuss A, Rizzo C, et al. 2015/16 IMOVE/I-MOVE+ multicentre case-control study in Europe: moderate vaccine effectiveness estimates against influenza a(H1N1)pdm09 and low estimates against lineage-mismatched influenza B among children. Influenza Other Respir Viruses. 2018;12(4):423-37.

38. Rondy M, Larrauri A, Casado I, Alfonsi V, Pitigoi D, Launay O, et al. 2015/16 seasonal vaccine effectiveness against hospitalisation with influenza
$A(\mathrm{H} 1 \mathrm{~N} 1) p d m 09$ and $\mathrm{B}$ among elderly people in Europe: results from the $\mathrm{I}-$ MOVE+ project. Euro Surveill. 2017;22(30):30580. https://doi.org/10.2807/ 1560-7917.ES.2017.22.30.30580

39. World Health Organization. Recommended composition of influenza virus vaccines for use in the 2015-2016 northern hemisphere influenza season. Wkly Epidemiol Rec. 2015;90(11):97-108.

40. Chen SY, Feng Z, Yi X. A general introduction to adjustment for multiple comparisons. J Thorac Dis. 2017:9(6):1725-9.

41. Rothman KJ. No adjustments are needed for multiple comparisons. Epidemiology. 1990;1(1):43-6.

42. Greenland S. Multiple comparisons and association selection in general epidemiology. Int J Epidemiol. 2008;37(3):430-4.

43. Pebody R, Warburton F, Ellis J, Andrews N, Potts A, Cottrell S, et al. Effectiveness of seasonal influenza vaccine for adults and children in preventing laboratory-confirmed influenza in primary care in the United Kingdom: 2015/16 end-of-season results. Euro Surveill. 2016;21(38):1-11.

44. Hannoun $\mathrm{C}$. The evolving history of influenza viruses and influenza vaccines. Expert Rev Vaccines. 2013;12(9):1085-94.

45. Ambrose CS, Levin MJ. The rationale for quadrivalent influenza vaccines. Hum Vaccin Immunother. 2012;8(1):81-8.

46. Belshe RB. The need for quadrivalent vaccine against seasonal influenza. Vaccine. 2010;28 Suppl 4:D45-53.

47. Sullivan SG, Cowling BJ. "Crude vaccine effectiveness" is a misleading term in test-negative studies of influenza vaccine effectiveness. Epidemiology. 2015;26(5):e60.

\section{Ready to submit your research? Choose BMC and benefit from:}

- fast, convenient online submission

- thorough peer review by experienced researchers in your field

- rapid publication on acceptance

- support for research data, including large and complex data types

- gold Open Access which fosters wider collaboration and increased citations

- maximum visibility for your research: over $100 \mathrm{M}$ website views per year

At $\mathrm{BMC}$, research is always in progress.

Learn more biomedcentral.com/submissions 